\title{
\begin{tabular}{l|l} 
MitTraries & DSpace@MIT
\end{tabular}
}

\author{
MIT Open Access Articles
}

\section{Enhancing Performance Stability of Electrochemically Active Polymers by Vapor-Deposited Organic Networks}

The MIT Faculty has made this article openly available. Please share how this access benefits you. Your story matters.

Citation: Mao, X., Liu, A., Tian, W., Wang, X., Gleason, K. K., Alan Hatton, T., Adv. Funct. Mater. 2018, 28, 1706028.

As Published: http://dx.doi.org/10.1002/adfm.201706028

Publisher: Wiley

Persistent URL: https://hdl.handle.net/1721.1/140443

Version: Author's final manuscript: final author's manuscript post peer review, without publisher's formatting or copy editing

Terms of use: Creative Commons Attribution-Noncommercial-Share Alike 


\title{
Article type: Full Paper
}

\section{Enhancing Performance Stability of Electrochemically Active Polymers by Vapor-Deposited Organic
Networks}

a

Xianwen Mao, Andong Liu, Wenda Tian, Xiaoxue Wang, Karen K. Gleason *, and T. Alan Hatton *

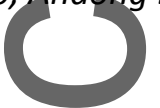

Dr. X. Mao, A. Kiu, W. Tian, X. Wang, Prof. K. K. Gleason, Prof. T. A. Hatton

Department of Chemical Engineering, Massachusetts Institute of Technology, 77 Massachusetts

Avenue, Cambridge, MA, 02139, United States

Email: kkg@mit.edu, tahatton@mit.edu

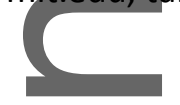

Keywords: electrochemically active polymers, performance stability, chemical vapor deposition, energy storage, flexible devices

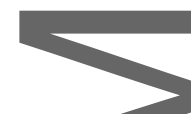

\begin{abstract}
Performance stability of electrochemically active polymers (EAPs) remains one of the greatest and long-standing challenges with regard to EAP-based technologies for a myriad of energy, biomedical, and environmental applications. The performance instability of EAPs originates from their structural alteration under repeated charge-discharge cycling and/or flexing. In this work, a conceptually new "soft confinement" strategy to enhance EAP performance stability, including cyclic and mechanical, by using rationally designed, vapor-deposited organic networks is presented. These chemically crosslinked networks, when in contact with an electrolyte solution, turn into ultrathin, elastic hydrogel coatings that encapsulate conformally the EAP micro/nanostructures. Such hydrogel coatings allow easy passage of ions that intercalate with EAPs, while simultaneously mitigating the structural pulverization of the EAPs and/or their detachment from substrates. Fundamentally distinct from extensively studied "scaffolding" or "synthetic" approaches to stabilizing EAPs, this soft confinement strategy relies on a post-modification step completely decoupled from the EAP
\end{abstract}

This is the author mal iscript accepted for publication and has undergone full peer review but has not been through wo proditing, typesetting, pagination and proofreading process, which may lead to differences betwe nis version and the Version of Record. Please cite this article as doi: $10.1002 / \mathrm{ar}+1.201706028$.

This article is protected by copyright. All rights reserved. 


\section{WILEY-VCH}

synthesis/fabrication, and enjoys the unique advantage of substrate-independency. Hence, this strategy is broadly applicable to various types of EAPs. The proposed stability enhancement strategy has been demonstrated to be effective for a range of EAP systems with differing chemical and morphological characteristics under various testing conditions (repeated charging/discharging, bending and twisting).

1. Introduction

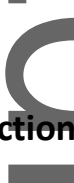

(

The growing research interest in electrochemically active polymers (EAPs) stems from their key roles in diverse applications, such as energy storage and conversion, ${ }^{[1-4]}$ drug delivery and monitoring, ${ }^{[5,6]}$ organic (bio)electronics development, ${ }^{[7,8]}$ neural interface engineering, ${ }^{[9,10]}$ and chemical and environmental separations. ${ }^{[11-13]}$ Performance stability remains one of the greatest and longstanding challenges with regard to EAP-based technologies, particularly with prolonged charge/discharge cycling and/or the application of mechanical stresses. Enhanced stability would enable practical long-term operation, as well as meet the increasing demand for flexible electronic devices ${ }^{[14-16]}$ Possible mechanisms causing the cycling instability of EAPs include structural pulverization due to repeated swelling and shrinkage of polymer backbones, and collapse of initially present ion channels resulting in difficulty of subsequent re-doping. ${ }^{[14,17-20]} \mathrm{A}$ widely adopted approach to enhancing EAP stability is integration of the EAPs with conductive scaffolds, such as porous graphite foams, ${ }^{[21]}$ carbon nanotube sponges, ${ }^{[22]}$ nickel foams, ${ }^{[23]}$ and partially exfoliated graphite.$^{[18]}$ These scaffolds are usually porous and dimensionally stable, and thus act as robust supports for EAP films to reduce their structural alteration. Such a "scaffolding" approach relies on effective-hybridization of the EAP with the underlying conductive substrate, a non-trivial task. The integration process often requires judicious surface modification of the scaffold materials to create specific interactions (e.g., covalent bonding, $\pi-\pi$ stacking) with the EAP, and a lengthy screening

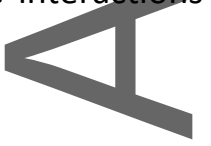

This article is protected by copyright. All rights reserved. 


\section{WILEY-VCH}

process to determine the reaction conditions for the growth of a certain EAP on the scaffold. A few less common methods based on deliberate synthetic strategies for improving EAP stability have also been demonstrated, such as creation of superamolecular structures, ${ }^{[24]}$ synthesis of hyperbranched EAPs, ${ }^{[25]}$ and dopant/EAP engineering. ${ }^{[26,27]}$ These scaffolding and synthetic approaches have shown great promise when applied to certain types of EAP systems, but are highly dependent on the chemical nature-of the EAP. Hence, an optimized reaction condition usually applies to only one specific EAR. In addition, morphology control of the EAP is not decoupled from the integration or synthesis process: the scaffolding or synthetic approach that results in enhanced stability could also yield an undesired morphology with compromised electrochemical properties (e.g., lower energy density, lower sensitivity, and diminished functionalities).

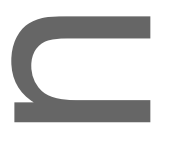

Here we reportaconcep

Here we report a conceptually new strategy to enhance EAP performance stability using a rationally designed polymer network that provides "soft confinement" for an EAP system. We hypothesize that an EAP system, whose microstructure is confined conformally by an ultrathin elastic polymer network, would exhibit increased morphological integrity, leading to low extents of structural pulverization and ion channel collapse. In contrast to the scaffolding and synthetic approaches studied extensively in the past, ${ }^{[18,21-27]}$ our soft confinement approach is applicable independently of the surface chemistry and morphology of the EAPs to be stabilized, and hence can be used flexibly in various types of EAP systems with different structures for a range of applications. The concept of soft confinement is illustrated schematically in Figure 1. To achieve effective stability enhancement without compromising the desired electrochemical functionalities of EAPs, the material system offering the soft confinement should be able to (i) completely and conformally coat the interfaces of This article is protected by copyright. All rights reserved. 


\section{WILEY-VCH}

micro-/nano-structured EAPs without blocking the structures/pores, (ii) tolerate the volumetric alteration of EAPs without being mechanically degraded itself, and (iii) allow easy passage of electrolyte ions for subsequent doping/de-doping of the inner EAPs. In this work, we designed a hydrogel coating that meets all the preceding requirements for soft confinement. Such a hydrogel coating was formed in an aqueous electrolyte by the swelling of a polymer network synthesized via a non-destructive gas-phase process, initiated chemical vapor deposition (iCVD).

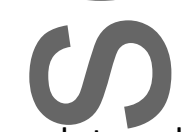

Our approach to enhancing EAP stability exhibits many advantages. First, the coating process using iCVD does not rely on the surface energy of the EAP. Nor does it depend on the surface chemistries of, or specific interactions with, the EAP, and thus is broadly applicable to EAPs of various chemical natures. It should be noted that our study focuses on electrochemically active polymeric systems, i.e. excluding other systems whereby electrochemical driving forces are absent, such as dielectric electroactive polymers for actuator applications. ${ }^{[28]}$ Furthermore, our polymer coating and the resulting hydrogel thin-film conform to a structured interface and therefore is applicable to highly porous, nanostructured EAP systems, which are of enormous significance for various electrochemical applications. This is because iCVD allows the conformal modification of pores with diameters down to sub-100 nm, with exquisite control of the coating thickness. ${ }^{[29,30]}$ Additionally, the coating process using vapor phase precursors is solvent-free, thus avoiding common issues associated with solutionbased modifications such as polymer leaching and deformation. It is also worth mentioning that iCVD, fundamentally different from high-temperature CVD, is thermally non-destructive and therefore can be applied to modify a fabricated EAP electrode in situ. Finally, yet importantly, the

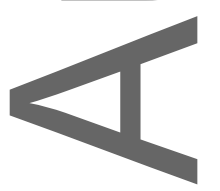

This article is protected by copyright. All rights reserved. 


\section{WILEY-VCH}

iCVD technique has proven scalability for potential commercialization; large-area batch $(>1 \mathrm{~m}$ diameter) and roll-to-roll systems have been utilized for manufacture. ${ }^{[31]}$

\section{Results and Discussion}
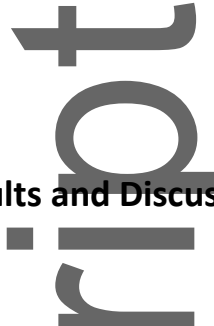

The prototype polymer network developed in our study to coat and stabilize EAPs is poly(2hydroxyethyl methacrylate) (PHEMA) cross-linked by di(ethylene glycol) divinyl ether (DEGDVE). The chemical cross-linking was deliberately introduced to enhance the structural stability of the resulting iCVD hydrogel. ${ }^{[32]}$ Hereafter the crosslinked PHEMA is denoted PHEMAx. As the first proof of concept, we studied the effects of the hydrogel coating on the electrochemical cyclic stability of a model EAP, polyvinylferrocene (PVF), which has various important electrochemical applications such as energy storage, ${ }^{[33]}$ biosensing, ${ }^{[34,35]}$ and redox-tunable catalysis ${ }^{[36]}$ and separation. ${ }^{[11,12]}$ Prior to the iCVD treatment, PVF was deposited potentiostatically on a conductive carbon paper (CP) substrate to generate a PVF/CP hybrid, which was subsequently transferred into an iCVD chamber for conformal coating of PHEMAx throughout the porous PVF/CP electrodes. Hereafter the nomenclature " $A / B$ " or " $A-h / B$ " is used to identify a multi-component construct, where " $A$ " indicates the active material system (e.g., an EAP), "A- $h$ " indicates A is modified with a PHEMAx coating that turns into a hydrogel upon contact with water, and " $\mathrm{B}$ " is the conductive substrate upon which $\mathrm{A}$ is deposited. The resulting PVF-h/CP system consisted of ternary core-shell fibers with individual components from the innermost being carbon fiber, PVF and PHEMAx. PHEMAx was selected as the polymer matrix for the soft confinement layer because of its ability to form a hydrogel upon swelling in aqueous electrolytes, allowing the transport of ions. ${ }^{[32,37]}$ The ultrathin hydrogel outermost layer,

This article is protected by copyright. All rights reserved. 


\section{WILEY-VCH}

which can be controlled precisely by iCVD, should not add a substantial resistance to the ion transport. More importantly, iCVD PHEMAx-based hydrogels generally exhibit moderate swelling ratios $(<1.55){ }^{[32]}$ which is crucial for our soft confinement concept; high water content would compromise the gel's mechanical strength whereas low water content would result in small mesh sizes and therefore high resistance to ion transport. The PHEMAx coating synthesized under our conditions had a-swelling ratio of $1.40 \pm 0.04$, corresponding to a mesh size of $3.12 \pm 0.66 \mathrm{~nm}$ based on the Flory-Huggins theory assuming uniaxial swelling of an elastic network (SI section S2). ${ }^{[37]}$ Such a mesh size would allow easy transport of most aqueous electrolyte ions for energy storage applications (SI Table S1); perchlorate and sulfate ions used in our study have hydrated ion sizes of 0.34 and $0.38 \mathrm{~nm}$, respectively. ${ }^{[38]}$ The Fourier transform infrared spectrum (FTIR) of PHEMAx confirms the retention of HEMA functional groups during iCVD synthesis (SI Figure S1a). The water contact angle of a PHEMAx film on a smooth silicon wafer was measured to be $20.70 \pm 0.12^{\circ}$ (SI Figure S1b), demonstrating the hydrophilicity of PHEMAx.

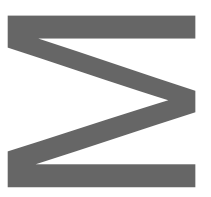

Scanning electron microscopic (SEM) imaging of CP, PVF/CP, and PVF-h/CP (Figure 2a, b and c, respectively) shows clear morphological differences across the three systems. Compared to bare CP, PVF/CP exhibits a larger fiber diameter and a rougher surface, indicating the presence of the PVF polymer. After being coated with PHEMAx, the fiber displays a further increase in diameter and a smoother surface, revealing a conformal PHEMAx layer wrapping around the PVF/CP fibers. X-ray photoelectron spectroscopic (XPS) survey scans of CP, PVF/CP, and PVF-h/CP are displayed in Figure 2d. PVF/CP shows pronounced $\mathrm{Fe}_{2 \mathrm{p} 1 / 2}$ and $\mathrm{Fe}_{2 \mathrm{p} 3 / 2}$ peaks at 715 and $705 \mathrm{eV}$, respectively, characteristic of ferrocene, while these peaks are completely absent for PVF-h/CP. This suggests

This article is protected by copyright. All rights reserved. 


\section{WILEY-VCH}

that, after the iCVD treatment, the surface of the PVF/CP network was fully covered by PHEMAx. Notably PVF-h/CP has an O/C ratio of $0.52 \pm 0.06$, consistent with the theoretical value $(0.5)$ for HEMA, corroborating that the outermost shell in PVF-h/CP consists mainly of PHEMA.

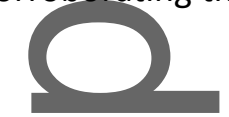

$\square$

Next, we tperformed electrochemical tests on PVF-h/CP. For details on all electrochemical measurements, see SI section S5. Throughout this report the current density (A/g) and specific capacity $(C / g)$ of each electrode system are reported with respect to the total mass of the polymer components, including both the EAP and the PHEMAx coating (if any), unless otherwise noted. Electrochemical cycling stability of PVF-h/CP was first examined using cyclic voltammetry (CV). As shown in Figure 2e, PVF/CP, without iCVD treatment, exhibits a significantly reduced specific capacity after 15000 cycles (only $12 \%$ retention), while PVF-h/CP with 1.5 to $4.5 \mathrm{~h}$ iCVD treatments shows virtually $100 \%$ capacity retention. With only $0.5 \mathrm{~h}$ iCVD treatment, improved stability relative to unmodified PVF/CP was still observed ( 54\% retention after 15000 cycles). It is imperative that the improved cycling stability not be at the expense of the specific capacities. From CVs obtained at the fifth cycle (i.e., before significant degradation occurred) (Figure 2f), we observed comparable current densities before and after the iCVD treatment, indicating that inclusion of the hydrogel layer did not reduce the specific capacities significantly. The difference in potential between the anodic and cathodic peaks in CVs $\left(\Delta E_{\mathrm{p}}\right)$ appeared to increase with the iCVD treatment, suggestive of increased ion diffusion resistance, which may affect rate capabilities. To evaluate the rate performance, we plot the specific capacity versus scan rates (Figure $\mathbf{2 g}$ ), from which it can be seen that with a prolonged iCVD treatment $(4.5 \mathrm{~h})$ a markedly jeopardized rate performance resulted. Therefore, 3 h appears to be an optimal iCVD treatment time that yields the best combination of

This article is protected by copyright. All rights reserved. 


\section{WILEY-VCH}

capacity retention and rate performance preservation. We observed slightly reduced specific capacities for the coated samples at low scan rates, because of the added weight of electrochemically inert PHEMAx component. If we normalize to the mass of PVF only, we actually obtain slightly increased specific capacities; for instance, the specific capacities obtained at $0.01 \mathrm{~V} / \mathrm{s}$ for PVF/CP and PVF-h/CP with a $3 \mathrm{~h}$ iCVD treatment are 33.4 and $35.7 \mathrm{C} / \mathrm{g}$, respectively. The surface covered by PHEMAx had a higher degree of hydrophilicity (water contact angle $=20.7^{\circ}$ ) than that covered by ferrocene (water contact angle $=71^{\circ}$ ); ${ }^{[35]}$ a hydrogel coating on PVF could facilitate its interaction with percholorate.

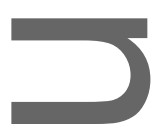

Having demonstrated the stabilizing effects of the $3 \mathrm{~h}$ iCVD PHEMAx, we hypothesize that, mechanistically, the soft confinent coating is able to confine PVF to the vicinity of its conductive networks even when it is pulverized, and therefore preserve its capacity upon cycling. To validate this hypothesis, we performed tensile tests on a simulated PHEMAx coating. The PHEMAx hydrogel can elongate $109 \%$ before it breaks; such a high elongation at break is sufficient to accommodate the volumetric swelling of the PVF film ( $32 \%$ ) (see SI Section S3 for a detailed discussion). ${ }^{[39]}$

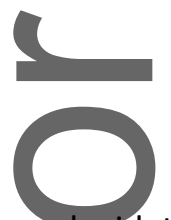

Further, we elucidated quantitatively the effects of the hydrogel coating on the electrochemical charge transport dynamics in PVF. Mechanistically, charge propagation in an EAP system with discrete redox sites (e.g., PVF) is a diffusive process that relies on sequential electron exchange between adjacent redox groups under restricted local motions of polymer chains. ${ }^{[19,40,41]}$ This diffusive process is usually described by an effective charge transport diffusion coefficient $\left(D_{\mathrm{ct}}\right)$. The

This article is protected by copyright. All rights reserved. 


\section{WILEY-VCH}

presence of the hydrogel coating would hinder diffusion of the counterion (i.e., perchlorate) from the bulk solution, and, consequently, would affect the charge transport kinetics of the PVF film, leading to lowered $D_{\text {ct }}$ values. Notably the rate of ion intercalation into the polymer film and subsequent binding with ferrocene governs the redox transformation kinetics of PVF. Experimentally, the hindered charge transport dynamics in PVF was manifested by the increased $\Delta E_{\mathrm{p}}$ values (Figure 2f) To quantify the effects of iCVD conditions on the charge transport dynamics (i.e., $D_{c t}$ values), we used a redox thin film (RTF) model ${ }^{[36,42-44]}$ (SI section S6) to simulate the instantaneous current responses of PVF during linear potential sweeping at varying scan rates $\left(v_{s}\right)$ using a series of different $D_{\mathrm{ct}}$ values. Figure $\mathbf{2 h}$ shows a heat map of simulated $\Delta E_{\mathrm{p}}-v_{\mathrm{s}}$ data with varying 6 , which is defined as the ratio of the $D_{\mathrm{ct}}$ value for pure PVF to the reduced $D_{\mathrm{ct}}$ value for PVF with a hydrogel coating (i.e., $b=D_{\mathrm{ct}}^{\mathrm{PVF}} / D_{\mathrm{ct}}^{\mathrm{PVF}-\mathrm{h}}$ ). On overlaying of the experimentally obtained $\Delta E_{\mathrm{p}}-v_{\mathrm{s}}$ data over the simulated heat map, we observed that, compared to untreated PVF, short iCVD treatments $(0.5$ to $3 \mathrm{~h})$ decreased $D_{\mathrm{ct}}$ by $\sim 20$ fold (i.e., $B \approx 20$ ) while a longer treatment $(4.5 \mathrm{~h})$ reduced $D_{\text {ct }}$ by $\sim 50$ fold.

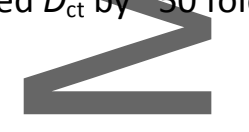

Galvanostatic (GV) cycling (SI Figure S2a) yielded conclusions consistent with the CV measurements (Figure 2e): the capacity retention after $10000 \mathrm{GV}$ cycles at $1.34 \mathrm{~A} / \mathrm{g}$ was $58 \%$ for PVF/CP without PHEMAx, whereas the capacity retention after $10000 \mathrm{GV}$ cycles at $1.23 \mathrm{~A} / \mathrm{g}$ was nearly $100 \%$ for PVFh/CP with a $3 \mathrm{~h}$ iCVD treatment. Electrochemical impedance spectroscopic (EIS) measurements (SI Figure S2b) show that the combined series resistances $\left(R_{s}\right)$ for PVF-h/CP with $0.5,1.5$ and $3 \mathrm{~h}$ treatments were $35.9,36.2$, and $37.4 \Omega$, respectively, close to the value for untreated PVF $(35.7 \Omega)$, whereas the $4.5 \mathrm{~h}$ treatment resulted in a larger $R_{\mathrm{s}}$ value $(54.1 \Omega)$.

This article is protected by copyright. All rights reserved. 


\section{WILEY-VCH}

Next, we investigate the applicability of our soft confinement approach for stabilizing EAPs beyond PVF. EAPs are categorized into two general classes: redox polymers with unconjugated backbones and intrinsically conducting polymers (ICPs) with conjugated backbones. ${ }^{[19,41]}$ The PVF films studied

$\square$

earlier belong to the first category. ICPs are also widely used in electrochemical applications and their performance stability is an even more severe issue than that of redox polymers because the rigid conjugated backbones make ICPs more prone to electrochemical degradation during cyclic operation. ${ }^{[19]}$ Hence, it was of interest to study whether our stabilization approach would be effective for ICPs. We used polypyrrole (PPY) as the model ICP system, which has been employed widely as the active component in energy storage devices. ${ }^{[18]}$ We first studied the impact of incorporation of PHEMAx on the cycling stability of PPY electrochemically deposited on CP. SEM images of PPY/CP and PPY-h/CP (3 h iCVD treatment) (Figure 3a, b) show clear morphological differences, indicating conformal coating of PHEMAx on top of PPY. XPS survey scans (Figure 3c) demonstrate that after the iCVD treatment, the $N_{1 s}$ peak disappears, confirming a complete coverage of the PPY layer by PHEMAx around the PPY-h/CP fibers. CV tests at $0.1 \mathrm{~V} / \mathrm{s}$ reveal that PPY-h/CP had significantly improved cycling stability, with $98 \%$ capacity retention compared to only 17\% retention for PPY/CP (Figure 3d). Notably, the PPY films deposited on CP exhibited a nonporous structure (see Figure 3a). Nanostructured ICPs possessing increased surface area and shortened ion diffusion pathways usually exhibit higher capacitances than do their nonporous counterparts; however, nanosized ICPs usually have more brittle structures, and therefore further deteriorated cycling stability. ${ }^{[14,20]}$ To investigate whether the PHEMAx coating can also improve cycling stability of nanostructured ICPs, we prepared freestanding nanostructured PPY gels (nPPY; Figure $3 e$ inset

This article is protected by copyright. All rights reserved. 


\section{WILEY-VCH}

shows photographs of free-standing pellet-like nPPY gels). SEM imaging shows that the as-prepared nPPY exhibits a porous structure comprised of spherical particles (Figure 3e). After the iCVD treatment, the particles present a more rounded morphology, indicating the existence of a PHEMAx coating (Figure 3f). The coating displays a high degree of conformality, showing practically no blockage of the pores, which is crucial for preserving the desired advantages of the porous nanostructures. The absence of a $N_{1 s}$ peak and the $\mathrm{O} / \mathrm{C}$ ratio being consistent with that of HEMA in the XPS spectrum of nPPY-h (Figure 3g) confirms that the interfaces in nPPY-h are completely covered by PHEMAx. Compared to nPPY, nPPY-h displays substantially improved cycling stability (Figure 3h). Importantly, for both the PPY and nPPY cases, we did not observe significantly compromised transport rates or increased resistances due to the iCVD treatment, as shown in Figure 3i, which summarizes the capacitance decay with increased operation rate (scan rate for CV or current density for $(\mathrm{GV})$, and the $R_{\mathrm{s}}$ values obtained from EIS. Plots of capacitance versus scan rate or current density, and EIS spectra are shown in SI Figure S5.

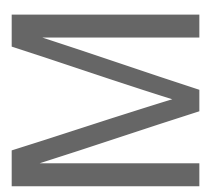

To confirm that the PHEMAx coating can mitigate the structural pulverization and/or detachment from the substrates, we investigate the morphologies of PHEMAx-coated EAPs and unmodified EAPs after electrochemical cycling experiments. The SEM images of PVF/CP, PVF-h/CP, PPY/CP and PPYh/CP before and after $10000 \mathrm{CV}$ cycles at $0.1 \mathrm{~V} / \mathrm{s}$ are shown in SI Figure S6. It can be seen clearly that after cycling experiments, the EAPs without PHEMAx underwent significant morphological variation and/or detached from the CP substrate whereas PHEMAx-coated EAPs maintained structural integrity.

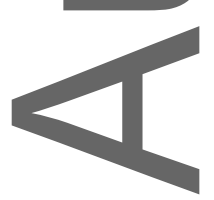

This article is protected by copyright. All rights reserved. 


\section{WILEY-VCH}

Recently, a demand for improving the mechanical stability of EAP systems under strained conditions has emerged for the development of flexible, bendable electronics. ${ }^{[8,16]}$ To show that the soft confinement approach is applicable for improving the mechanical stability of EAPs under strained

conditions, we conducted bending and twisting tests for PHEMAx-coated PVF and PPY (representing redox polymers and ICPs, respectively) integrated into a flexible carbon cloth (CC) substrate. A bending cycle is defined as the compressive flexing of the the electrode with a mechanical tester from over a range of angles from $180^{\circ}$ to $100^{\circ}$ (radius $=3 \mathrm{~mm}$ ) and then a return of the electroded to its original position (Figure 4a). The thickness of the electrode was $\sim 0.4 \mathrm{~mm}$, estimated from the SEM cross-sectional analysis (SI Figure S7a), so the maximum strain during bending was $6.7 \%$ (for calculation details, see $\mathbf{S I}$ Figure $\mathbf{S 7 b}$ ). Figure $\mathbf{4 b}$ shows the capacitance retention versus number of bending cycles for PVF/CC, PVF-h/CC, PPY/CC and PPY-h/CC. Without the hydrogel coating, PVF/CC showed only $59.3 \%$ capacity retention after 3000 bending cycles, possibly due to the expected stress-induced detachment of polymer films from CC yarns under strained conditions. In contrast, PVF-h/CC showed remarkably improved capacity retention $(90.8 \%)$ after the same number of bending cycles, demonstrating that the robust soft confinement reduces the degree of EAP detachment. Similar results were observed for PPY-based systems: after 2500 bending cycles, PPY/CC retained only $41.7 \%$ of its initial specific capacity whereas PPY-h/CC preserved $93.1 \%$ of its initial specific capacity. We further performed twisting tests whereby each twisting cycle is defined as the retation of $1 \mathrm{~cm} \times 16 \mathrm{~cm}$ electrode by $360^{\circ} \times 8=2880^{\circ}$ with a controlled electrical drill followed by a return to its original position (Figure 4c). The twisted electrode took on a cyclinder-like

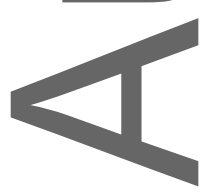

This article is protected by copyright. All rights reserved. 


\section{WILEY-VCH}

shape with an average diameter of $\sim 4.5 \mathrm{~cm}$, consistent with a maximum strain of $8.9 \%$ during twisting (for calculation details, see SI Figure S7c).

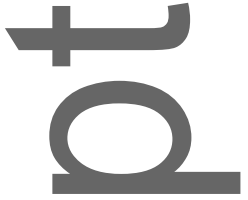

The capacity retentions of PVF/CC, PVF-h/CC, PPY/CC and PPY-h/CC after 600 such twisting cycles (Figure 4d) were calculated to be $63.6 \%, 95.7 \%, 46.7 \%$ and $93.7 \%$, respectively, demonstrating that the samples with the hydrogel coating exhibited a stronger preservation of their energy storage performance under twisting conditions. Composite materials containing EAP and "nano-fillers" such as carbon nanotubes and activated carbon usually display high energy densities and excellent rate performance. ${ }^{[14,20]}$ These materials are, however, more susceptible to mechanical stress since these "nano-fillers" fall off their substrates easily. ${ }^{[45]}$ Therefore, we moved on to investigate if our EAP stabilization approach would be effective for EAP/nanofiller composites. We modified CC substrates with nanocomposites consisting of PVF and metallic carbon nanotubes (CNTs) by electrochemical deposition from stable suspensions containing PVFCNT complexes formed via the strong $\pi$-stacking interaction between the cyclopentadiene rings of PVF and the $\mathrm{sp}^{2}$-carbon surfaces of CNTs. ${ }^{[46]}$ The resulting PVFCNT nanocomposites (polymer to CNT mass ratio $\approx 4$ ) typically exhibited pores with an average diameter of $~ 50-100 \mathrm{~nm}$ and BET surface area of $112 \mathrm{~m}^{2} / \mathrm{g} .{ }^{[46]}$ Compared to PVF/CC and PPY/CC, PVFCNT showed poorer performance stability under strained conditions (Figure 4e): the capacity retention of PVFCNT/CC was $31.6 \%$ after 2400 bending cycles and $23.5 \%$ after 550 twisting cycles. Remarkably, the encapsulation of PVFCNT nanocomposites with a hydrogel coating led to significantly improved performance stability: the capacity retentions for PVFCNT-h/CC after the same bending and twisting tests as for PVFCNT/CC were $89.7 \%$ and $82.1 \%$, respectively.

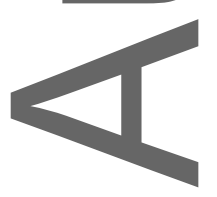

This article is protected by copyright. All rights reserved. 


\section{WILEY-VCH}

To demonstrate the effectiveness of the soft confinement strategy in practical energy storage devices, we constructed a flexible solid-state asymmetrical supercapacitor (ASC) and studied the influence of the PHEMAx coating on its performance stability. ASC modified with PHEMAx is denoted $\square$ -

as ASC-h. The ASC (Figure 5a) consisted of PVFCNT as the positive electrode and poly(3,4ethylenedioxythiophene) (PEDOT) synthesized by oxidative chemical vapor deposition (OCVD) as the negative electrode. The asymmetrical configuration was adopted to enhance the energy densities by providing matching operating potential ranges between the positive and negative electrodes (SI section S7). As controls, we prepared symmetric PVFCNT and PEDOT supercapacitors. CV profiles (Figure 5b) show that the asymmetrical devices yielded significantly higher current densities than those obtained with the symmetric devices. Notably, the asymmetric devices exhibited the desired redox peaks of ferrocene whereas the symmetric devices failed to produce such redox peaks. For comparison, CVS of PEDOT and PVFCNT in a three-electrode configuration are shown in Figure 5c and $\mathbf{d}$, respectively. The Ragone plot (Figure 5e) shows that ASC and ASC-h achieved maximum energy densities of 32.4 and $31.2 \mathrm{Wh} / \mathrm{kg}$, respectively, significantly larger than the values for symmetrical devices with either PEDOT (3.37 Wh/kg) or PVFCNT (6.26 Wh/kg). The capacitance retentions of ASC and ASC-h after 10000 GV charging/discharging cycles, 4000 bending cycles, and 800 twisting cycles (rotation span $=360^{\circ} \times 1 / 2=180^{\circ}$ ) are summarized in Figure $\mathbf{5 f}$, based on which it is evident that incorporation of PHEMAx improved the performance stability significantly. The capacitance retentions versus the number of GV cycles, bending cycles, and twisting cycles are shown in SIFigure $\mathbf{8} \mathbf{8} \mathbf{a}, \mathbf{b}$ and c, respectively.

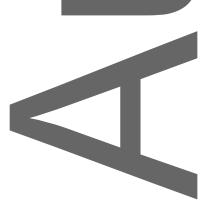

This article is protected by copyright. All rights reserved. 


\section{WILEY-VCH}

\section{Conclusion}

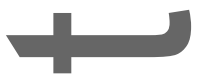

In conclusion, we have developed a "soft confinement" approach to improving EAP performance stability by using iCVD-synthesized PHEMAx films that, when in contact with electrolyte solutions, become hydrogel coatings encapsulating the EAP microstructures. Fundamentally distinct from commonly used "scaffolding" or "synthetic" approaches, our strategy enjoys the unique advantage of substrate-independency, and hence is broadly applicable to EAPs of different chemical characteristics and morphologies. We have demonstrated that our strategy led to remarkably enhanced performance stabilities of different types of EAP systems, under various testing conditions, including repeated charging/discharging, bending and twisting. We anticipate that our soft confinement approach could also be used in combination with other EAP stabilization methods, taking the performance stability of EAPs to a higher level. Furthermore, our strategy could be extended to many other EAP applications beyond energy storage, where the stabilization and reusability of EAPS are crucial for realizing practical long-term operations. Such applications may include EAP-based electrochemically mediated sensing, catalysis and separations, since the hydrogel coatings can be rationally engineered by modulating iCVD precursors and conditions for tunable chemical compositions and mesh sizes. The engineered coating could accommodate the key species that interact with the EAPs for these applications, such as target biomolecules to be detected for sensing purposes, reactants of interest in catalytic cycles, or pollutants to be removed in separation processes.

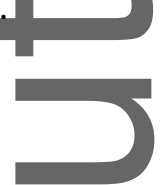

4. Experimental Section

This article is protected by copyright. All rights reserved. 


\section{WILEY-VCH}

Materials: Polyvinylferrocene (PVF, molecular weight $=50,000 \mathrm{~g} \mathrm{~mol}^{-1}$ ) was obtained from Polysciences. Pyrrole, sodium perchlorate, tetrabutylammonium (TBA) perchlorate, chloroform, ethanol, sulfuric acid, tert-butyl peroxide (TBPO) (98\%), 2-hydroxyethyl methacrylate (HEMA) ( $\geq$ 99\%), di(ethylene glycol) divinyl ether (DEGDVE) (99\%), 3,4-ethylenedioxythiophene (EDOT) (97\%), polyvinyl alcohol $\left(\mathrm{PVA}\right.$, molecular weight $\left.=61,000 \mathrm{~g} \mathrm{~mol}^{-1}\right)$, 2 2-dimethoxy-2-phenylacetophenone (DMPA, 99\%, Aldrich), multi-walled carbon nanotubes (MWCNTs) with a diameter of 6 to $9 \mathrm{~nm}$ and purity of $95 \%$ were obtained from Sigma Aldrich. A platinum wire auxiliary electrode and an $\mathrm{Ag} / \mathrm{AgCl}$ ( $3 \mathrm{M} \mathrm{NaCl}$ ) reference electrode were purchased from BASi. All reagents were used as received throughout the study, without further purification or chemical modification unless otherwise noted.

Synthesis of EAP Systems: The typical procedure used to perform electrochemical deposition of EAPs onto carbon substrates is as follows. The PVF/CP or PVF/CC electrode system was prepared by applying a potential of $0.8 \mathrm{~V}$ versus $\mathrm{Ag} / \mathrm{AgCl}$ to the $\mathrm{CP}$ or $\mathrm{CC}$ substrate with a nominal surface area of $1 \mathrm{~cm}^{2}$ for $10 \mathrm{~min}$ in $5 \mathrm{ml}$ chloroform solution containing $10 \mathrm{mg} / \mathrm{ml} \mathrm{PVF}$ and $0.1 \mathrm{M}$ tetrabutylammonium perchlorate. The affinity of ferrocene moieties in PVF for hydrophobic organic solvents (e.g., chloroform) is reduced upon oxidation. Therefore, PVF initially soluble in chloroform became solvophobic and subsequently precipitated onto the fiber when it was oxidized at the fiber surface. The PPY/CP or PPY/CC electrode system was prepared by electrochemical polymerization of pyrrole through application of a potential of $0.6 \mathrm{~V}$ versus $\mathrm{Ag} / \mathrm{AgCl}$ to the $\mathrm{CP}$ or $\mathrm{CC}$ substrate for $5 \mathrm{~min}$ in $5 \mathrm{ml}$ water containing $0.1 \mathrm{M}$ pyrrole and $0.1 \mathrm{M}$ sodium perchlorate. The PVFCNT/CC electrode system was prepared by repeating the following electrochemical deposition for several times: application of a potential of $0.8 \mathrm{~V}$ versus $\mathrm{Ag} / \mathrm{AgCl}$ to the $\mathrm{CC}$ substrate with a nominal surface area of $1 \mathrm{~cm}^{2}$ for $2 \mathrm{~min}$ in $5 \mathrm{ml}$ chloroform solution containing $10 \mathrm{mg} / \mathrm{ml} \mathrm{PVF}, 2 \mathrm{mg} / \mathrm{mL}$ MWCNTs, and $0.1 \mathrm{M}$

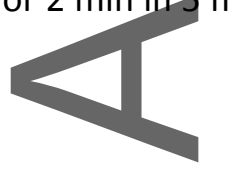

This article is protected by copyright. All rights reserved. 


\section{WILEY-VCH}

tetrabutylammonium perchlorate. Typically, the deposition process was repeated for three to four times, and between each deposition cyclic voltammetric measurements were performed to track the quantity of PVF deposited.Note that MWCNTs and PVF formed stable suspensions in chloroform after sonication for $45 \mathrm{~min} .{ }^{[46]}$ In a typical synthesis of nanostructured PPY hydrogels, $6.3 \mathrm{mmol}$ pyrrole was dissolved in $3 \mathrm{ml}$ water/ethanol ( $\mathrm{v} / \mathrm{v}$ 1:1) mixed solvent (solution A). Solution B was

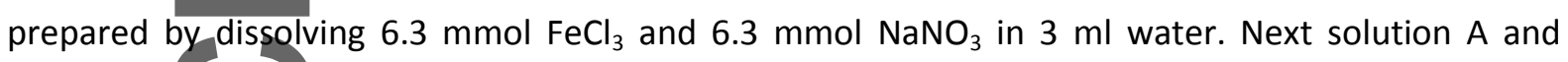
solution $\mathrm{B}$ were cooled to $0-4{ }^{\circ} \mathrm{C}$, and then mixed under vigorous agitation. The mixture was stored at room temperature for 30 days and the resulting PPY hydrogel was purified by immersion in a water/ethanol mixed solvent under stirring for $24 \mathrm{~h}$. Finally, the dehydrated PPY hydrogel was obtained by allowing it to dry in a vacuum oven at $60^{\circ} \mathrm{C}$ for $48 \mathrm{~h}$.

Synthesis of PHEMAx by Initiated Chemical Vapor Deposition (iCVD): The iCVD process and its reactor configuration have been described in detail elsewhere. ${ }^{[4]}$ PHEMAx was synthesized and simultaneously deposited onto porous EAP electrodes via iCVD. A silicon wafer was also placed in the reactor to harvest iCVD-deposited polymer, for the purpose of in situ thickness monitoring and polymer characterization. The monomer HEMA (heated at $75^{\circ} \mathrm{C}$ ) was delivered in the vapor phase introduced to the iCVD reactor at $0.45 \mathrm{sccm}$, together with the crosslinker DEGDVE (heated at $60^{\circ} \mathrm{C}$ ) at $0.3 \mathrm{sccm}$. The vapor of initiator TBPO was metered at $1.0 \mathrm{sccm}$. The reactor pressure was controlled at 300 mTorr by a throttle valve. The stage temperature was back-cooled and maintained at $40{ }^{\circ} \mathrm{C}$. The filament temperature was heated resistively at $250{ }^{\circ} \mathrm{C}$. For PVF/CP electrodes, four treatment times $(0.5,1.5,3$, and $4.5 \mathrm{~h})$ were investigated. For all other electrodes, $3 \mathrm{~h}$ of iCVD treatment was used.

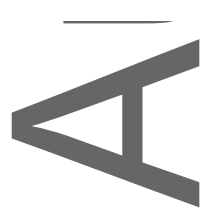

This article is protected by copyright. All rights reserved. 


\section{WILEY-VCH}

Fabrication of the Solid-State Flexible Supercapacitor: The solid-state supercapacitor (symmetric or asymmetric) was assembled by two pieces of EAP-integrated CC electrodes on either side of a separator (VWR ${ }^{\circledast}$ Grade 415 Filter Paper) with a $\mathrm{H}_{2} \mathrm{SO}_{4} / \mathrm{PVA}$ gel as the solid electrolyte. The $\mathrm{H}_{2} \mathrm{SO}_{4} / \mathrm{PVA}$ gel was prepared by mixing concentrated sulfuric acid, PVA, and deionized water (mass ratio $=1: 1: 10)$ and heating at $90^{\circ} \mathrm{C}$ under stirring for $1 \mathrm{~h}$. The two electrodes and separator were soaked in the hot gel for about $5 \mathrm{~min}$ and then assembled together. The as-prepared device was kept in an oven at $65{ }^{\circ} \mathrm{C}$ for $24 \mathrm{~h}$ to remove excess water in the electrolyte, and then sealed with parafilm to prevent water absorption.

\section{Supporting Information}

Supporting Information is available from the Wiley Online Library or from the author.

\section{Acknowledgements}

X.M. and A.L. contributed equally to this work. The authors thank Dr. Jose Yagüe at Institut Quimic de Sarria for his generous help with mesh size calculation. Hongmou Zhang from the Department of Urban Studies and Planning at Massachusetts Institute of Technology is acknowledged for help with the visuals

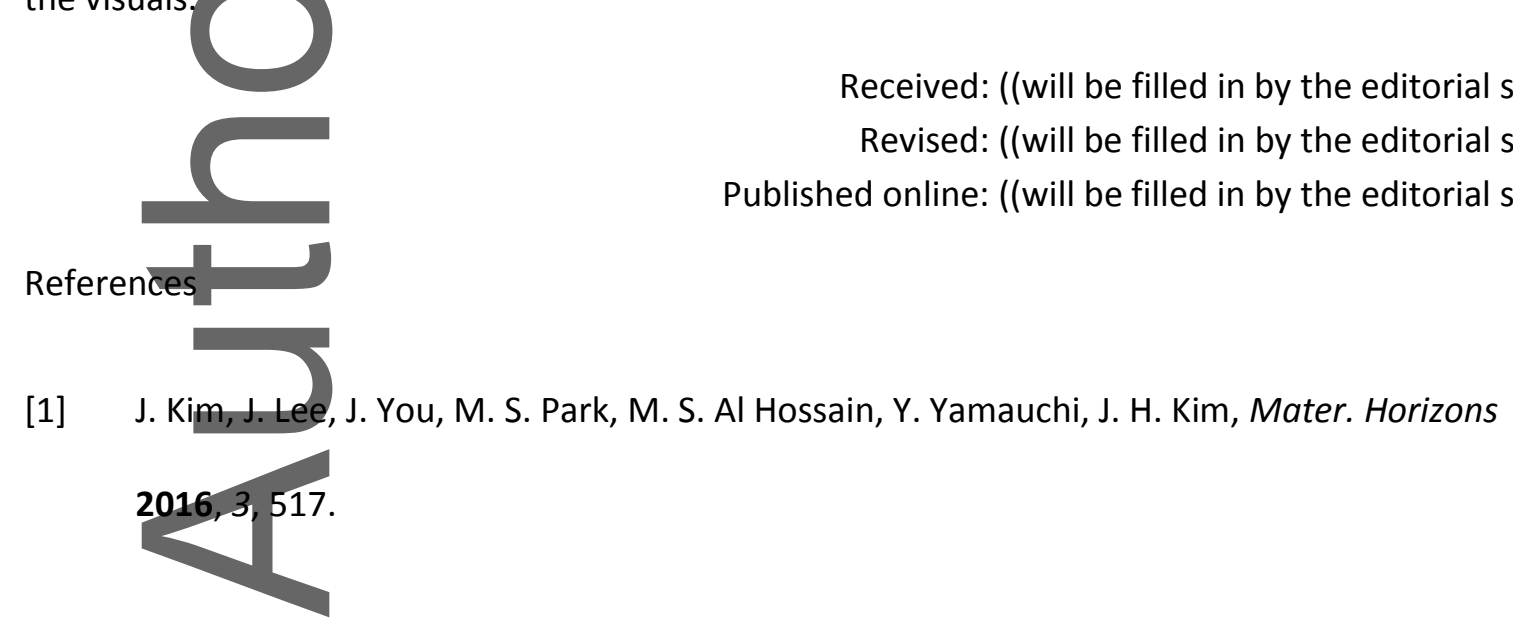

This article is protected by copyright. All rights reserved. 


\section{WILEY-VCH}

[2] S. Holliday, R. S. Ashraf, A. Wadsworth, D. Baran, S. A. Yousaf, C. B. Nielsen, C.-H. Tan, S. D. Dimitrov, Z. Shang, N. Gasparini, M. Alamoudi, F. Laquai, C. J. Brabec, A. Salleo, J. R. Durrant, I. McCulloch, Nat. Commun. 2016, 7, 11585.

[3] B. Russ, A. Glaudell, J. J. Urban, M. L. Chabinyc, R. A. Segalman, Nat. Rev. Mater. 2016, 1, 16050.

[4] A. Liu, P. Koyacik, N. Peard, W. Tian, H. Goktas, J. Lau, B. Dunn, K. K. Gleason, Adv. Mater. $2017,29,1606091$.

[5] D. Svirskis, J. Travas-Sejdic, A. Rodgers, S. Garg, J. Control. Release 2010, 146, 6.

[6] R. Feiner, L. Engel, S. Fleischer, M. Malki, I. Gal, A. Shapira, Y. Shacham-Diamand, T. Dvir, Nat. Mater. 2016, 15, 679.

[7] J. Y. Oh, S. Rondeau-Gagne, Y. C. Chiu, A. Chortos, F. Lissel, G. J. N. Wang, B. C. Schroeder, T. Kurosawa, J. Lopez, T. Katsumata, J. Xu, C. X. Zhu, X. D. Gu, W. G. Bae, Y. Kim, L. H. Jin, J. W. Chung, J. B. H. Tok, Z. N. Bao, Nature 2016, 539, 411.

[8] T. Someya, Z. N. Bao, G. G. Malliaras, Nature 2016, 540, 379.

[9] R. Green, M. R. Abidian, Adv. Mater. 2015, 27, 7620.

[10] W. B. Guo, X. D. Zhang, X. Yu, S. Wang, J. C. Qiu, W. Tang, L. L. Li, H. Liu, Z. L. Wang, ACS Nano $2016,10,5086$.

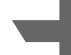

[11] X. Su, K.-J. Tan, J. Elbert, C. Ruttiger, M. Gallei, T. F. Jamison, T. A. Hatton, Energy Environ. Sci. $2017,10,1272$.

This article is protected by copyright. All rights reserved. 


\section{WILEY-VCH}

[12] X. Su, H. J. Kulik, T. F. Jamison, T. A. Hatton, Adv. Funct. Mater. 2016, 26, 3394.

[13] D. S. Achilleos, T. A. Hatton, ACS Appl. Mater. Interfaces 2016, 8, 32743.

[14] Y. Shi, L. L. Peng, Y. Ding, Y. Zhao, G. H. Yu, Chem. Soc. Rev. 2015, 44, 6684.

[15] C. O. Baker, X. Huang, W. Nelson, R. B. Kaner, Chem. Soc. Rev. 2017, 46, 1510.

[16] B. C. Kim, J.-Y. Hong, G. G. Wallace, H. S. Park, Adv. Energy Mater. 2015, 5, 1500959.

[17] T. Y. Liu, L. Finn, M. H. Yu, H. Y. Wang, T. Zhai, X. H. Lu, Y. X. Tong, Y. Li, Nano Lett. 2014, 14, 2522

[18] Y. Song, T. Y. Liu, X. X. Xu, D. Y. Feng, Y. Li, X. X. Liu, Adv. Funct. Mater. 2015, 25, 4626.

[19] G. Inzelt, In Conducting Polymers: A New Era in Electrochemistry; Springer Berlin Heidelberg: Berlin, Heidelberg, 2012; pp. 83-147.

[20] S. Ghosh, T. Maiyalagan, R. N. Basu, Nanoscale 2016, 8, 6921.

[21] X. H. Xia, D. L. Chao, Z. X. Fan, C. Guan, X. H. Cao, H. Zhang, H. J. Fan, Nano Lett. 2014, 14, 1651.

[22] W. Q. Zhao, S. S. Wang, C. H. Wang, S. T. Wu, W. J. Xu, M. C. Zou, A. Ouyang, A. Y. Cao, Y. B. Li, Nanoscale 2016, 8, 626.

[23] C. Zhou, Y. W. Zhang, Y. Y. Li, J. P. Liu, Nano Lett. 2013, 13, 2078.

[24] W. Li, F. Gao, X. Wang, N. Zhang, M. Ma, Angew. Chemie Int. Ed. 2016, 55, 9196.

[25] D. F. Zeigler, S. L. Candelaria, K. A. Mazzio, T. R. Martin, E. Uchaker, S. L. Suraru, L. J. Kang, G.

This article is protected by copyright. All rights reserved. 


\section{WILEY-VCH}

Z. Cao, C. K. Luscombe, Macromolecules 2015, 48, 5196.

[26] G.-F. Chen, X.-X. Li, L.-Y. Zhang, N. Li, T. Y. Ma, Z.-Q. Liu, Adv. Mater. 2016, 28, 7680.

[27] D. Vonlanthen, P. Lazarev, K. A. See, F. Wudl, A. J. Heeger, Adv. Mater. 2014, 26, 5095.

[28] F. Carpi, D. De Rossi, R. Kornbluh, R. E. Pelrine, P. Sommer-Larsen, Dielectric Elastomers as Electromechanical Transducers: Fundamentals, Materials, Devices, Models and Applications of an Emerging Electroactive Polymer Technology; Elsevier: Amsterdam, 2008.

[29] A. Asatekin, K. K. Gleason, Nano Lett. 2011, 11, 677.

[30] M. Wang, X. Wang, P. Moni, A. Liu, D. H. Kim, W. J. Jo, H. Sojoudi, K. K. Gleason, Adv. Mater. 2017, 29, 1604606.

[31] A. M. Coclite, R. M. Howden, D. C. Borrelli, C. D. Petruczok, R. Yang, J. L. Yagüe, A. Ugur, N. Chen, S. Lee, W. J. Jo, others, Adv. Mater. 2013, 25, 5392.

[32] K. Chan, K.K. Gleason, Langmuir 2005, 21, 8930.

[33] W. D. Tian, X. W. Mao, P. Brown, G. C. Rutledge, T. A. Hatton, Adv. Funct. Mater. 2015, 25, 4803.

[34] X. Mao, E.H. Yan, G. C. Rutledge, T. A. Hatton, Chem. Mater. 2016, 28, 543.

[35] R. Pietschnig, Chem. Soc. Rev. 2016, 45, 5216.

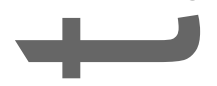

[36] X. Mao, W. Tian, J. Wu, G. C. Rutledge, T. A. Hatton, J. Am. Chem. Soc. 2015, 137, 1348.

[37] J. L. Yague, K. K. Gleason, Soft Matter 2012, 8, 2890.

This article is protected by copyright. All rights reserved. 


\section{WILEY-VCH}

[38] C. Zhong, Y. Deng, W. Hu, J. Qiao, L. Zhang, J. Zhang, Chem. Soc. Rev. 2015, 44, 7484.

[39] J. M.Cooper, R. Cubitt, R. M. Dalgliesh, N. Gadegaard, A. Glidle, A. R. Hillman, R. J. Mortimer, K. S Ryder, E. L. Smith, J. Am. Chem. Soc. 2004, 126, 15362.

[40] M. E. G. Lyons, In Advances in Chemical Physics; Prigogine, I.; Rice, S. A., Eds.; John Wiley \& Sons, Inc., 1996; pp. 297-624.

[41] C. Gabrielli, H. Perrot, In Modern Aspects of Electrochemistry No. 44: Modelling and Numerical Simulations II; Schlesinger, M., Ed.; Springer: New York, NY, 2009; pp. 151-238.

[42] A. J. Bard, L. R. Faulkner, Electrochemical methods: fundamentals and applications; 2 nd ed.; John Wiley \& Sons, Inc.: New York, NY, 2001.

[43] A. Merz, A. J. Bard, J. Am. Chem. Soc. 1978, 100, 3222.

[44] P. J. Peerce, A. J. Bard, J. Electroanal. Chem. Interfacial Electrochem. 1980, 114, 89.

[45] X. Zhang, L. Wang, J. Peng, P. Cao, X. Cai, J. Li, M. Zhai, Adv. Mater. Interfaces 2015, 2, 1500267.

[46] X. Mao, G. C. Rutledge, T. A. Hatton, Langmuir 2013, 29, 9626.

[47] K. K. S. Lau, K. K. Gleason, Macromolecules 2006, 39, 3688.

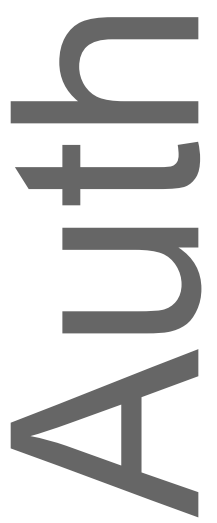

This article is protected by copyright. All rights reserved. 


\section{WILEY-VCH}

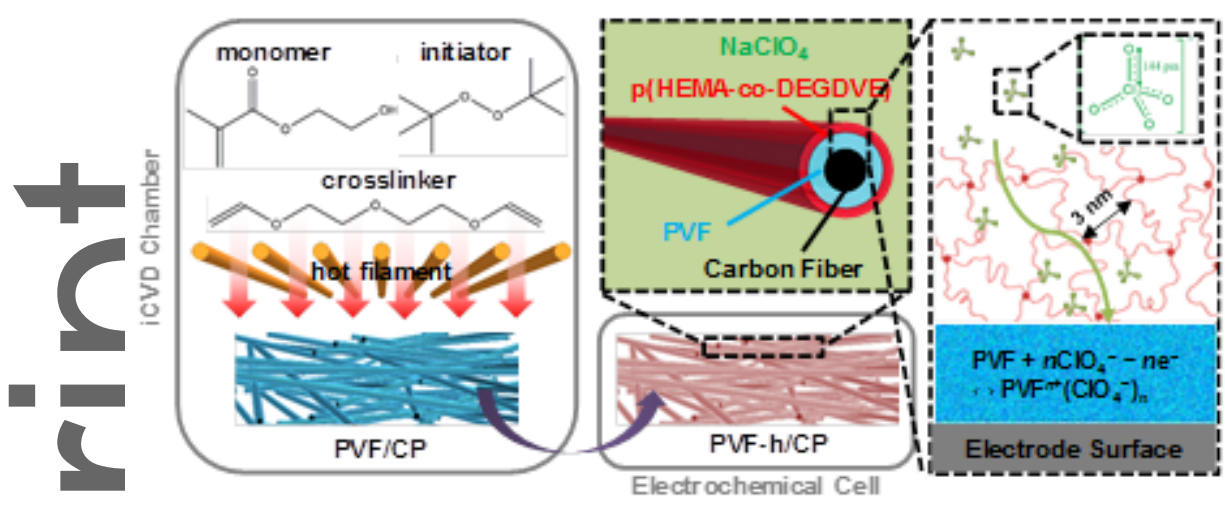

Figure 1. (a) Schematic illustration of the "soft confinement" concept. An iCVD-synthesized polymer network is deposited conformally on EAP microstructures. Here P(HEMA-Co-DEGDVE) (or PHEMAx) and PVF were used as the model polymer network and EAP, respectively.
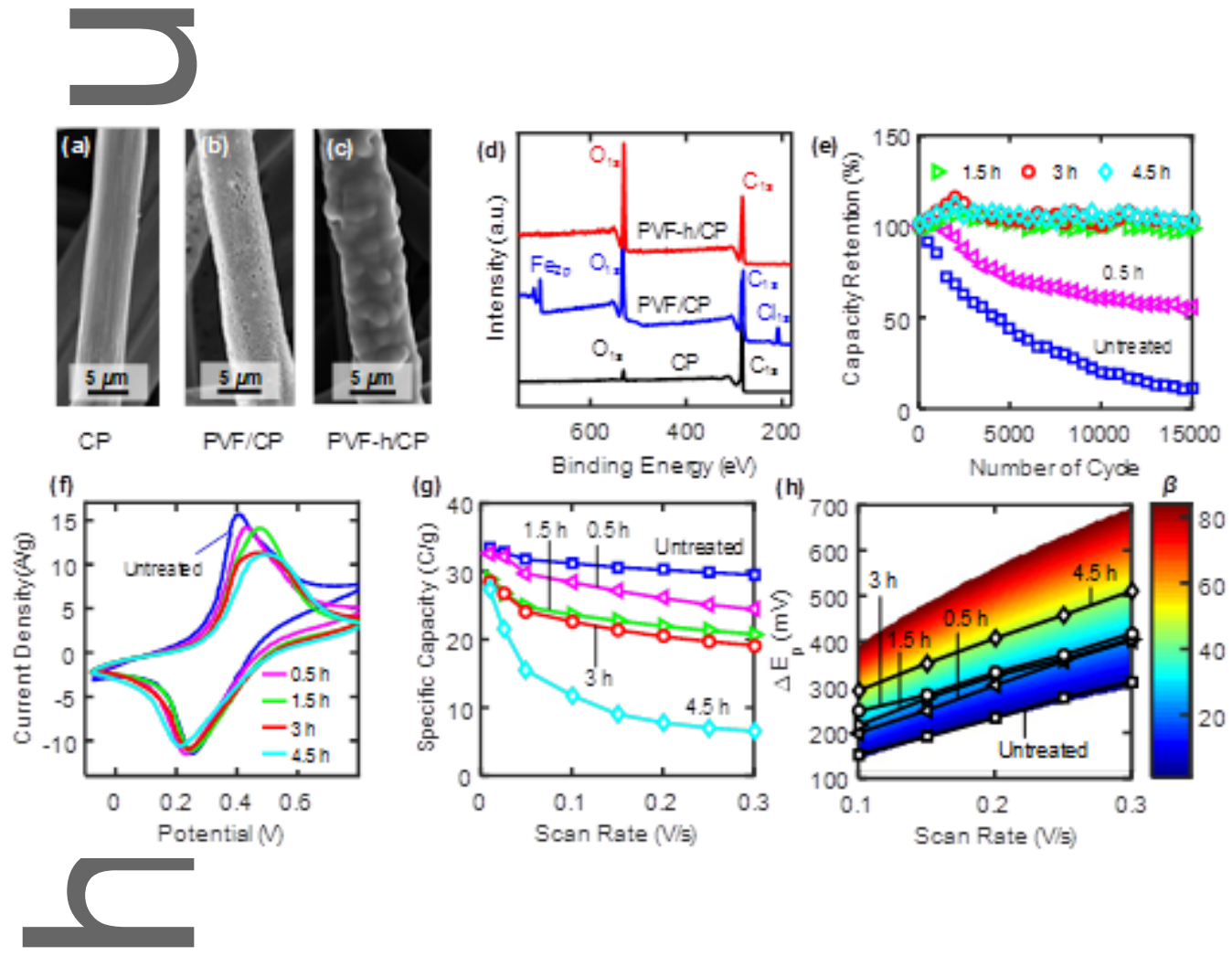

Figure 2. $(a-c)$ Representative SEM images of (a) bare CP (b) PVF/CP and (c) PVF-h/CP (3 h iCVD treatment). (d) XPS spectra of bare CP, PVF/CP and PVF-h/CP (3 h iCVD treatment). (e) Capacity retention versus the number of $\mathrm{CV}$ cycles, (f) CV curves during the fifth cycle, and (g) specific capacity versus scan rate for PVF/CP (untreated) and PVF-h/CP with 0.5, 1.5, 3 and $4.5 \mathrm{~h}$ iCVD treatments. $\mathrm{CV}$ was performed at $0.1 \mathrm{~V} / \mathrm{s}$ in $0.5 \mathrm{M} \mathrm{NaClO}_{4}$ using a three-electrode configuration. (h)

This article is protected by copyright. All rights reserved. 


\section{WILEY-VCH}

Simulated $\Delta E_{\mathrm{p}}$ values versus scan rate with different $B=D_{\mathrm{ct}}{ }^{\mathrm{PVF}} / D_{\mathrm{ct}}{ }^{\mathrm{PVF}-\mathrm{h}}$ values (heat map), overlaid with the experimentally measured $\Delta E_{\mathrm{p}}$ values (black symbols).

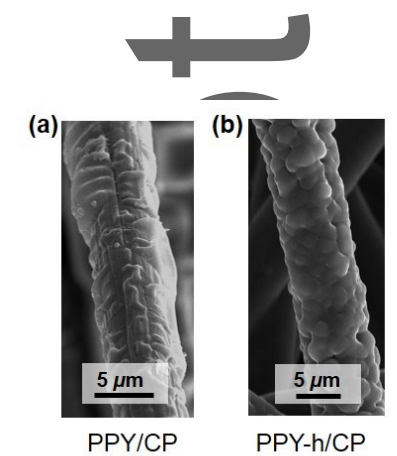

(f)

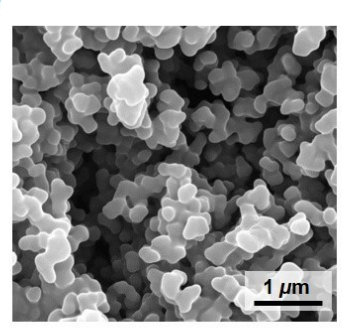

nPPY-h

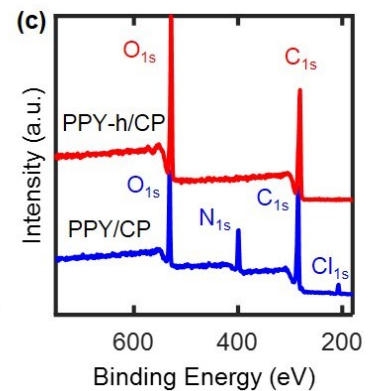

(g)

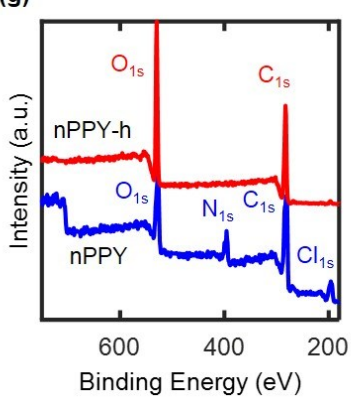

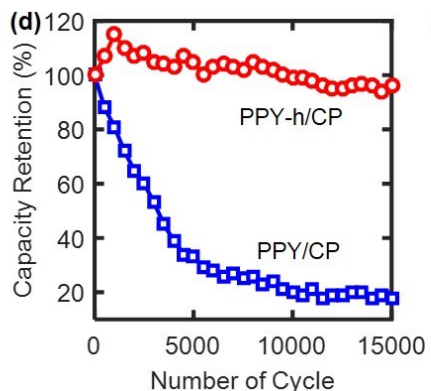

(e)

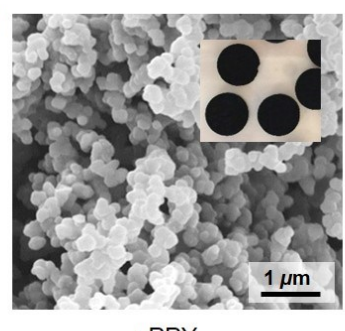

nPPY

(h)

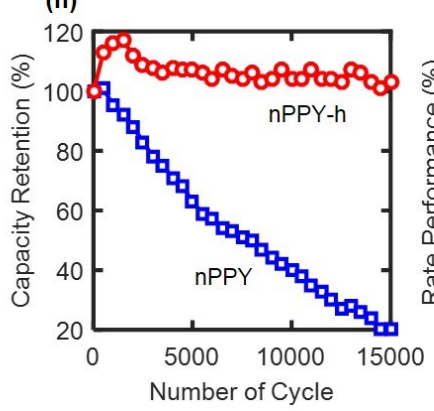

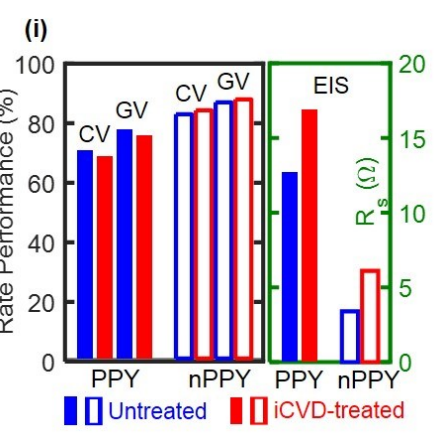

Figure 3. ( $a, b)$ Representative SEM images of (a) PPY/CP and (b) PPY-h/CP. (c) XPS spectra of PPY/CP and PPY-h/CP. (d) Capacity retention versus number of CV cycles for PPY/CP and PPY-h/CP. CV was performedat $0.1 \mathrm{~V} / \mathrm{s}$ in $0.5 \mathrm{M} \mathrm{NaClO}_{4}$ using a three-electrode configuration. (e) Representative SEM image of nPPY. Inset: photographs of freestanding nPPY pellets with a diameter of $\sim 9 \mathrm{~mm}$. (f) Representative SEM image of nPPY-h. (g) XPS spectra of nPPY and nPPY-h. (h) Capacity retention versus number of CV cycles for nPPY and nPPY-h. CV was performed at $0.1 \mathrm{~V} / \mathrm{s}$ in $0.5 \mathrm{M} \mathrm{NaClO}_{4}$ using a three-electrode configuration. (i) Summary of rate performance (left panel, measured by CV and $\mathrm{GV}$ ) and $R_{\mathrm{s}}$ values (right panel, measured by EIS) for PPY and $\mathrm{nPPY}$ without (blue bars) and with iCVD treatment (red bars). Rate performance measured by CV or GV measurements was defined as the ratio between the specific capacitance obtained at $0.2 \mathrm{~V} / \mathrm{s}$ or $\sim 5 \mathrm{~A} / \mathrm{g}$ and that obtained at $0.01 \mathrm{~V} / \mathrm{s}$ or $\sim 1 \mathrm{~A} / \mathrm{g}$. The PHEMAx coatings of PPY-h/CP and $\mathrm{nPPY}-\mathrm{h}$ were prepared by a $3 \mathrm{~h}$ iCVD treatment.

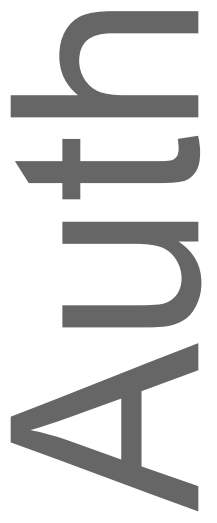

This article is protected by copyright. All rights reserved. 


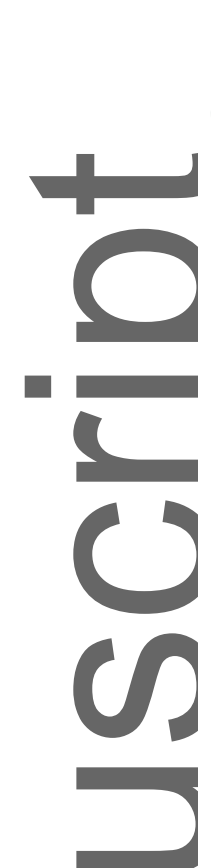

(a)

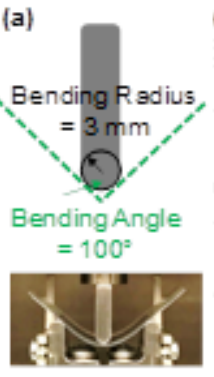

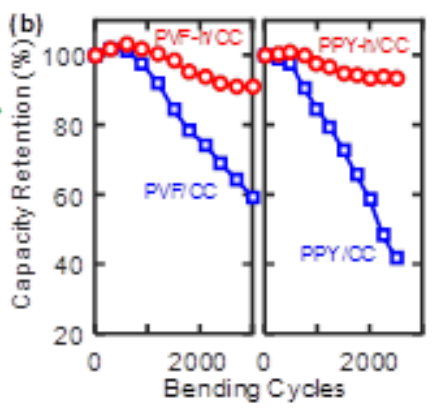

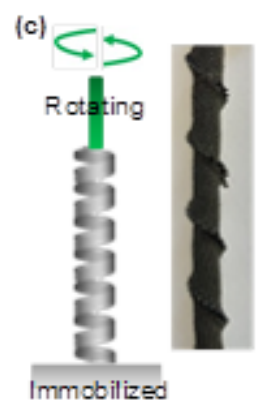

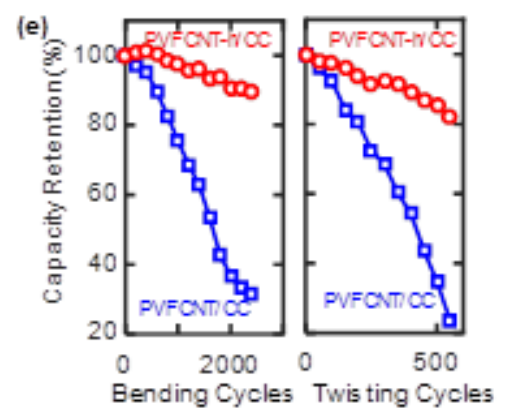

Figure 4. (a) Schematic illustration of the bending test condition. Photograph shows an example of a bent electrode. (b) Capacity retention versus number of bending cycles for PVF/CC, PVF-h/CC, $\mathrm{PPY} / \mathrm{CC}$, and PPY-h/CC. Specific capacities were measured by $\mathrm{CV}$ at $0.15 \mathrm{~V} / \mathrm{s}$ in $0.5 \mathrm{M} \mathrm{NaClO}_{4}$ using a three-electrode configuration. (c) Schematic illustration of the twisting test conditions. Photograph shows an example of a twisted electrode. (d) Capacity retention versus number of twisting cycles for $\mathrm{PVF} / \mathrm{CC}, \mathrm{PVF}-\mathrm{h} / \mathrm{CC}, \mathrm{PPY} / \mathrm{CC}$, and PPY-h/CC. Specific capacities were measured by CV at $0.15 \mathrm{~V} / \mathrm{s}$ in 0.5 $\mathrm{M} \mathrm{NaClO}_{4}$ using a three-electrode configuration. (e) Capacity retention versus number of bending or twisting cycles for PVFCNT/CC and PVFCNT-h/CC.

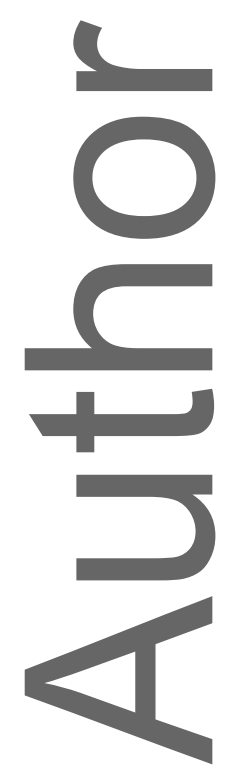

This article is protected by copyright. All rights reserved. 


\section{WILEY-VCH}
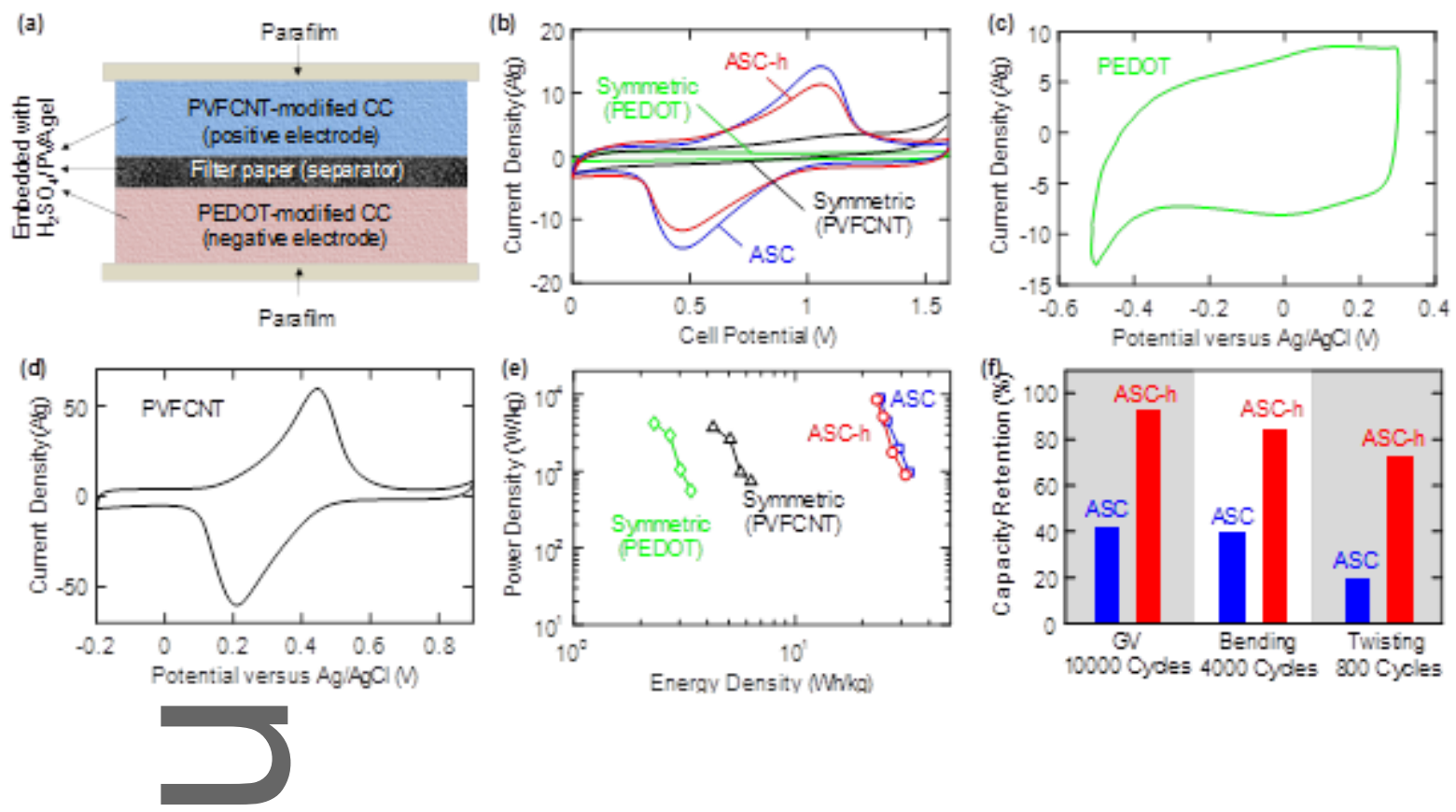

Figure 5. (a) Schematic illustration of the flexible solid-state asymmetric supercapacitor that consists of a PVFCNT-h positive electrode and a PEDOT-h negative electrode. (b) CV curves $(0.05 \mathrm{~V} / \mathrm{s})$ obtained with a symmetric PEDOT supercapacitor, symmetric PVFCNT supercapacitor, ASC and ASCh. (c) CV curve of a PEDOT electrode obtained in $1 \mathrm{M} \mathrm{H}_{2} \mathrm{SO}_{4}$ at a scan rate of $0.05 \mathrm{~V} / \mathrm{s}$ with a threeelectrode configuration. (d) $\mathrm{CV}$ curve of a PVFCNT electrode obtained in $1 \mathrm{M} \mathrm{H}_{2} \mathrm{SO}_{4}$ at a scan rate of $0.05 \mathrm{~V} / \mathrm{s}$ with a three-electrode configuration. (e) Ragone plots for the symmetric PEDOT, PVFCNT supercapacitors, ASC and ASC-h. (f) Comparison of capacity retention between ASC and ASC-h when subject to $10000 \mathrm{GV}$ cycles, 4000 bending cycles, and 800 twisting cycles. GV measurements were performed at $1.2 \mathrm{~A} / \mathrm{g}$ for ASC and $1.4 \mathrm{~A} / \mathrm{g}$ for ASC-h. For bending and twisting tests, the specific capacities were determined by CV measurements at $0.1 \mathrm{~V} / \mathrm{s}$. The PHEMAx coatings of PVF-h/CC, PPYh/CC, PVF-CNT-h/CC and ASC-h were prepared by a $3 \mathrm{~h}$ iCVD treatment.

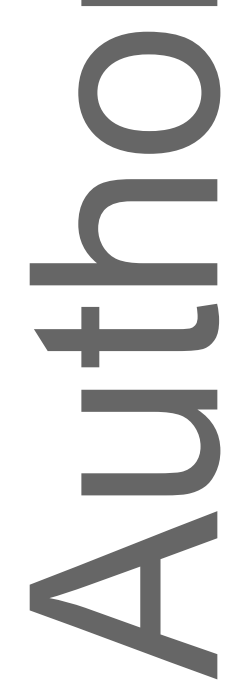

This article is protected by copyright. All rights reserved. 


\section{WILEY-VCH}

"Soft confinement" approach to improved performance stability of electrochemically active polymers (EAPs) is achieved by vapor-deposited organic networks that, when in contact with electrolyte solutions, become ultrathin hydrogels encapsulating conformally micro-/nano-structured EAPs. Bymodulating precursors and vapor deposition conditions, the resulting hydrogel coatings can give suitable mesh sizes to accommodate the key species that interact with the EAPs.

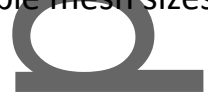

Key words: electrochemically active polymers, performance stability, chemical vapor deposition, energy storage, flexible devices

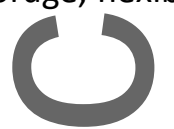

Xianwen Mao, Andong Liu, Wenda Tian, Xiaoxue Wang, Karen K. Gleason", and T. Alan Hatton ${ }^{*}$

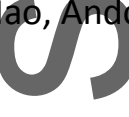

Enhancing Performance Stability of Electrochemically Active Polymers by Vapor-Deposited Organic Networks

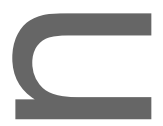

ToC figure (55 $\mathrm{mm}$ broad $\times 50 \mathrm{~mm}$ high)

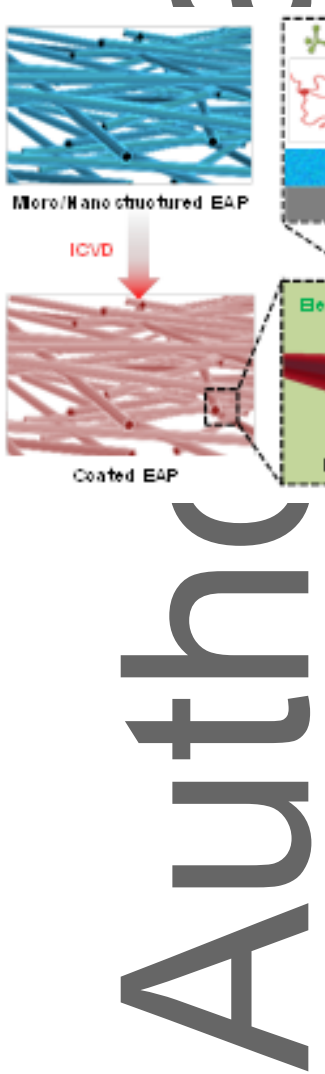

This article is protected by copyright. All rights reserved. 


\section{WILEY-VCH}

((Supporting Information can be included here using this template))

Copyright WILEY-VCH Verlag GmbH \& Co. KGaA, 69469 Weinheim, Germany, 2016.

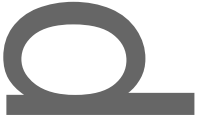

$\square$

Supporting Information

Enhancing Performance Stability of Electrochemically Active Polymers by Vapor-Deposited Organic Networks

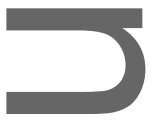

Xianwen Mao, Andong Liu, Wenda Tian, Xiaoxue Wang, Karen K. Gleason", and T. Alan Hatton *

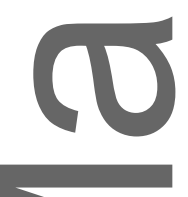

Table of Contents

Section S1 General Instrumentation

Section S2 Estimation of the Hydrogel Mesh Size

Section S3 Estimation of the Elongation at Break of the PHEMAx Hydrogels

Section S4 Synthesis of PEDOT by Oxidative Chemical Vapor Deposition (oCVD)

Section S5 Electrochemical Characterization and Data Processing

Section 66 Redox Thin Film (RTF) Simulation

Section S7 Asymmetric Supercapacitor Design to Enhance Energy Densities

Section S8 Supplementary Figures and Tables

Section S9 References for the Supporting Information

This article is protected by copyright. All rights reserved. 


\section{WILEY-VCH}
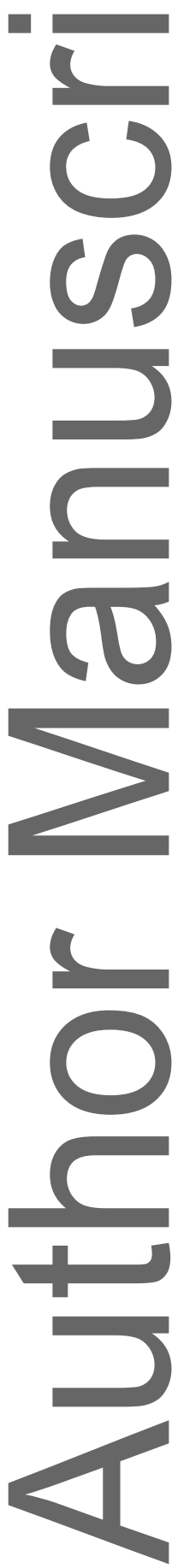

This article is protected by copyright. All rights reserved. 


\section{WILEY-VCH}

\section{Section S1 General Instrumentation}

Scanning electron microscopy (SEM) (JEOL-6010LA) was used for the morphological study of various EAP-based electrode systems. Samples for SEM were sputter-coated with a $10 \mathrm{~nm}$ layer of gold/palladium using a Desk II cold sputter/etch unit (Denton Vacuum LLC). X-ray photoelectron spectroscopy (XPS, Kratos Analytical) measurements were recorded with a Kratos Axis Ultra instrument equipped with a monochromatic $\mathrm{Al} \mathrm{K \alpha}$ source operated at $150 \mathrm{~W}$. The analyzer angle was set at 90 degrees with respect to the specimen surface. Survey scan spectra were recorded over a binding energy range of 0-800 eV and pass energy of $160 \mathrm{eV}$. Energy calibration for the XPS survey scans was performed by setting the carbon line to $284.0 \mathrm{eV}$. To obtain the $\mathrm{O} / \mathrm{C}$ ratio, the XPS survey scans were analyzed using CasaXPS software (Shirley background). Variable-angle ellipsometric spectroscopy (VASE, M-2000, J.A. Woollam) was used to measure the dry and swollen film thicknesses at the angle incidence of $70^{\circ}$. Water contact angle measurements were conducted for the iCVD coating on silicon wafer substrate with a goniometer equipped with an automatic dispenser (Rame-Hart, model 500). The static sessile drop method was applied. A water volume of $2 \mu \mathrm{L}$ was deposited on the sample surface and the contact angle was determined based on the high resolution image. FTIR measurement were performed on a Nicolet iS50 FT-IR Spectrometer (Thermo Scientific) equipped with a MCT detector and $\mathrm{KBr}$ beam splitter in normal transmission mode. The spectra of iCVD coated wafers were collected, and those of uncoated silicon wafers were subtracted as background. Measurements were taken over $350-3500 \mathrm{~cm}^{-1}$ with a resolution of $4 \mathrm{~cm}^{-1}$ and averaged over 256 scans to improve signal-to-noise ratio. All spectra were baseline-corrected. The surface area of the porous carbon paper substrate was determined from nitrogen adsorption isotherm (ASAP2020, Micromeritics) by means of the Brunauer-Emmett-Teller (BET) method.

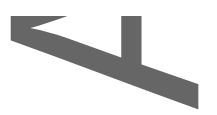

This article is protected by copyright. All rights reserved. 


\section{WILEY-VCH}

Thermogravimetric analysis (TGA) experiments were carried out using a TA Q50 instrument. Before the TGA experiment, the sample was dried in a vacuum oven at $50^{\circ} \mathrm{C}$ for $12 \mathrm{hr}$. Then the sample was placed into a TGA pan and stabilized at $30{ }^{\circ} \mathrm{C}$ for $30 \mathrm{~min}$, and the temperature was increased to 800 ${ }^{\circ} \mathrm{C}$ at a heating rate of $5{ }^{\circ} \mathrm{C} / \mathrm{min}$. Electrochemical characterization was performed using a VersaSTAT4 potentiostat with the VersaStudio software. Compressive bending tests were performed using an ADMET micro EP miniature testing machine. The machine was programed to repeat the bending for a specified number of cycles. Twisting tests were carried out using a controllable electrical drilling machine (Mile-X) to rotate the flexible electrodes at one end with the other end immobilized.

\section{Section S2 Estimation of the Hydrogel Mesh size}

To estimate the thickness of dry films, the ellipsometric data were obtaiend directly and fit to the Cauchy-Urbach model. ${ }^{[1]}$ For swollen thickness measurement, a liquid cell accessory (J.A. Woollam) was used. The cell was clamped over the sample, and water was injected to the liquidtight cell. A correction was applied to account for the effect from the cell windows. The optical properties of water were incorporated into the fitting of ellipsometric data to the Cauchy-Urbach model. The model and method to calculate mesh sizes of hydrogels are described in detail elsewhere. ${ }^{[1]}$

\section{Section S3 Estimation of the Elongation at Break of the PHEMAx Hydrogels}

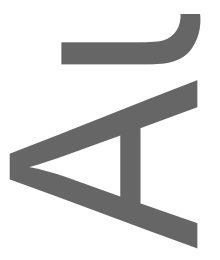

This article is protected by copyright. All rights reserved. 


\section{WILEY-VCH}

PHEMAx hydrogel strips mimicking the composition of iCVD PHEMAx hydrogel coatings were prepared in order to estimate the elongation at break of the coatings. The ratio between the concentration of monomer HEMA and that of crosslinker DEGDVE absorbed on the substrate surface under the iCVD condition was estimated to be $\sim 25: 1$, following a well-established method. ${ }^{[2]}$ According to this ratio, HEMA, DEGDVE (4 mol\% based on HEMA), photoinitiator DMPA (0.5 wt \% based on HEMA), and DI water (40 vol\% based on HEMA) were mixed and stirred until complete dissolution. The mixture was transferred into a cast composed of two glass plates separated by 1 $\mathrm{mm}$ spacer and subsequently irradiated by $365 \mathrm{~nm}$ UV light for $30 \mathrm{~min}$. The resulting PHEMAx strips were immersed in deionized water for 24 hours in order to remove unreacted monomers and establish swelling equilibrium. The tensile tests were conducted on these samples with an ADMET micro EP miniature testing machine.

The elongation at break of the PHEMAx hydrogels was determined to be $109 \pm 6 \%$ (Figure S3a). In theory, such an elastic coating can ensure that the EAP is confined closely to its conductive network if it tends to pulverize. For example, in the PVF-h/CP system, the CP substrate consists of carbon fibers with an average diameter of $7.78 \mu \mathrm{m}$, whereas the PVF coating has an average thickness of $0.315 \mu \mathrm{m}$ (Figure S4). When the PVF film is completely oxidized, its volume can increase by $32 \%,{ }^{[3]}$ translating to $2.2 \%$ increase in the circumference of the PVF film around the carbon fiber based on the geometry of our PVF-h/CP system (see the schematic in Figure S3b). Therefore, the PHEMAx hydrogel coating, whose circumference can stretch by $109 \%$, is capable of accommodating the swelling of the underlying PVF layer without being degraded mechanically. Thus, the soft elastic confinement is able to prevent the detachment of the PVF from the CP substrate during

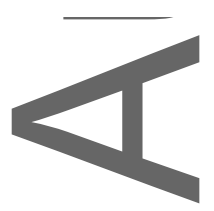

This article is protected by copyright. All rights reserved. 


\section{WILEY-VCH}

electrochemical cycling, which is directly evident from the morphological changes before and after cycling (Figure S6).

\section{Section S4 Synthesis of PEDOT by Oxidative Chemical Vapor Deposition (oCVD)}

The OCVD process procedure and the reactor configuration are described in detail elsewhere. ${ }^{[4]}$ Briefly, 3,4-ethylenedioxythiophene monomer was evaporated at $140{ }^{\circ} \mathrm{C}$ and metered at $\sim 2 \mathrm{sccm}$. $\mathrm{FeCl}_{3}$ oxidant was controllably evaporated from a resistively heated crucible at $\sim 230{ }^{\circ} \mathrm{C}$. The total pressure was maintained $\sim 1$ mTorr. 1 by $2 \mathrm{~cm}$ carbon cloth (CC) substrates were taped onto a heated stage at $80^{\circ} \mathrm{C}$. The reactions were allowed $20 \mathrm{~min}$. Last, samples were thoroughly rinsed by methanol and dried in a fume hood overnight.

\section{Section S5 Electrochemical Characterization and Data Processing}

All electrochemical experiments were performed on a VersaSTAT4 potentiostat with a standard three-electrode or two-electrode configuration. In a three-electrode configuration, an $\mathrm{Ag} / \mathrm{AgCl}(3 \mathrm{M}$ $\mathrm{NaCl}$ ) electrode (BASi) and a platinum wire were used as the reference electrode and the counter electrode, respectively. The electrochemical impedance spectroscopy (EIS) measurements were carried out using a $10 \mathrm{mV}$ applied $\mathrm{AC}$ voltage from $100 \mathrm{kHz}$ to $100 \mathrm{mHz}$ employing an electrochemical impedance analyzer.

The specific capacitance of a single electrode $\left(C_{\text {single }}\right)$ derived from cyclic voltammetry (CV) in a three-electrode configuration was calculated as: ${ }^{[5]}$

This article is protected by copyright. All rights reserved. 


\section{WILEY-VCH}

$$
C_{\text {single }}=\frac{\int_{V_{1}}^{V_{2}}\left(i_{a}(V)-i_{c}(V)\right) d V}{2\left(V_{2}-V_{1}\right) m_{\text {single }} v}
$$

where $V_{1}$ and $V_{2}$ are the cutoff potentials in cyclic voltammetry, $i_{a}(V)$ and $i_{c}(V)$ are the instantaneous anodic and cathodic currents as functions of potential, $v$ is the scan rate, and $m_{\text {single }}$ is the mass of the EAPs for untreated samples and EAPs + PHEMAx for samples treated by iCVD in the working electrode. The specific capacitance of a single electrode derived from galvanostatic (GV) measurements in a three-electrode configuration was calculated as: ${ }^{[6]}$

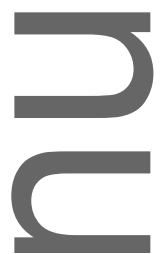

$$
C_{\text {single }}=\frac{I \Delta t}{m_{\text {single }} \Delta V}
$$

where $I$ is the discharge current, $\Delta t$ is the discharge time, $\Delta V$ is the voltage change, and $m_{\text {single }}$ is the mass of the active material (i.e. electrochemically active polymer) on the working electrode. The specific charge capacity $(\mathrm{C} / \mathrm{g})$ was obtained through multiplication of the specific capacitance $(\mathrm{F} / \mathrm{g})$ by the potential range.

In a two-electrode configuration, the specific capacitance of the supercapacitor cell $\left(C_{\text {cell }}\right)$ derived from cyclic voltammetry was calculated as: $:^{[5]}$

$$
C_{\text {cell }}=\frac{\int_{V_{1}}^{V_{2}}\left(i_{a}(V)-i_{c}(V)\right) d V}{2\left(V_{2}-V_{1}\right) m_{b o t h} v}
$$

where $m_{\text {both }}$ is the total mass of the EAPs or EAP + PHEMAx on both electrodes. The specific capacitance of the supercapacitor cell derived from GV measurements was calculated as: ${ }^{[6]}$

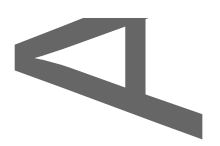

This article is protected by copyright. All rights reserved. 


\section{WILEY-VCH}

$$
C_{\text {cell }}=\frac{I \Delta t}{m_{\text {both }} \Delta V}
$$

The energy density $(E)$ of the supercapacitor cell derived from GV cycling was calculated from:

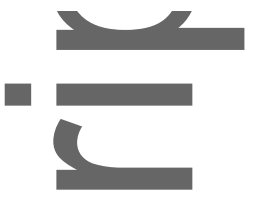

$$
E=\frac{I}{m_{\text {both }}} \int V(t) d t
$$

where $V(t)$ is the instantaneous voltage during the discharge process. The power density $(P)$ was calculated
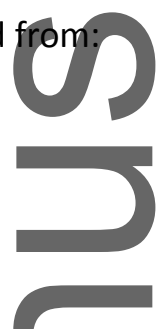

$$
P=\frac{E}{\Delta t}
$$

\section{Section S6 Redox Thin Film (RTF) Simulation}

To elucidate the effects of the hydrogel coating on the charge transport process of the underlying redox polymer film, we performed redox thin film (RTF) simulations to study the relationship between the effective charge transport diffusion coefficient $\left(D_{\mathrm{ct}}\right)$ and the separation in potential between the anodic and cathodic peak $\left(\Delta E_{\mathrm{p}}\right)$ that is directly observable from cyclic voltammetric experiments. The RTF model considers two fundamental processes that occur in an electro-active polymer film composed of discrete redox moieties: i) heterogeneous electron transfer at the interface between the polymer and the electrode, and ii) a diffusional charge transport process through the bulk polymer film. ${ }^{[7]}$ The presence of a conformal hydrogel coating on the PVF film presumably will slow down the diffusional charge transport in the bulk polymer film. In order for the ferrocene moieties to become oxidized, they need to be coupled with the anion (i.e., perchlorate

This article is protected by copyright. All rights reserved. 


\section{WILEY-VCH}

in our experiments) from the bulk electrolyte solution. Therefore, if the hydrogel coating acted as a barrier for the perchlorate diffusion, the charge transport dynamics in the polymer film would be hampered. This phenomenon should translate into a larger charge transfer resistance, manifested by a larger $\Delta E_{\mathrm{p}}$. The detailed procedure for the RTF simulations is documented in our previous work. ${ }^{[8]}$ Briefly, the RTF model uses the Butler-Volmer kinetic formulism to describe the heterogeneous electron transfer process at the electrode/polymer interface (a transfer coefficient of 0.5 is assumed in our calculations and a standard electron transfer rate constant of $k^{0}=1.2 \times 10^{4} \mathrm{~s}^{-1}$ for ferrocene was used), ${ }^{[9]}$ and use the diffusional kinetics (i.e., Fick's law) to depict the charge transport in the bulk polymer film (a $D_{\mathrm{ct}}$ value of $1.1 \times 10^{-9} \mathrm{~cm}^{2} / \mathrm{s}$ was used for PVF without PHEMAx based on literature results on PVF films with perchlorate as the counterion). ${ }^{[10]}$ The redox film is divided into $L_{\max }$ layers with an interlayer distance of $d_{\mathrm{L}}$; each layer contains an identical number of redox moieties. We used a $d_{\mathrm{IL}}$ value of $2 \mathrm{~nm}$ for the calculations of PVF films; note that the choice of this value only marginally affected the relation between $D_{\mathrm{ct}}$ and the $\Delta E_{\mathrm{p}}{ }^{8}$ The value of $L_{\max }$ was obtained by fitting the model to the experimentally determined $D_{\mathrm{ct}}-\Delta E_{\mathrm{p}}$ relation. Note that the $L_{\max }$ values are assumed to be the same for PVF/CP and PVF-h/CP with different iCVD treatment times since the PVF coating around the carbon fibers was prepared using the same potentiostatic deposition time (10 $\mathrm{min}$ ) under identical experimental conditions.

\section{Section S7 Asymmetric Supercapacitor Design to Enhance Energy Densities}

The enhancement of energy densities in supercapacitor devices is key to realizing their commercialization for practical applications such as hybrid electrical vehicles, self-powered portable

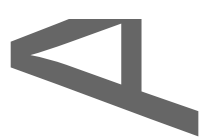

This article is protected by copyright. All rights reserved. 


\section{WILEY-VCH}

devices, and many other heavy-duty renewable energy systems. ${ }^{[11-17]}$ Energy densities $(E)$ can be enhanced by increasing the specific capacitance $(C)$ and/or widening the operating potential window $(V)$, according to the $E=\left(C V^{2}\right) / 2 \cdot{ }^{[18]}$ The use of asymmetric supercapacitors (ASCs) would allow for a significantly widened potential window if a positive electrode and a negative electrode were to be combined appropriately. ${ }^{[19,20]}$ We used the PVFCNT composite as the positive electrode because it had been found to exhibit significantly higher energy densities than PVF alone without the CNT component. ${ }^{[21]}$ However, it should be noted that, based on the measurements conducted in a threeelectrode configuration, the CV profile of PVFCNT (main text Figure 5d) had high current densities only in the potential range from $\sim 0$ to $0.6 \mathrm{~V}$ versus $\mathrm{Ag} / \mathrm{AgCl}$, the range over which the redox reaction of ferrocene occurs. It can be clearly seen from Figure $\mathbf{S 5}$ c that at the potentials lower than $0 \mathrm{~V}$ or higher than $0.6 \mathrm{~V}$, the current densities decreased significantly. If a symmetric configuration was adopted (i.e., using PVFCNT as both the positive and negative electrodes), the negative electrode that was forced to work in the potential range lower than $0 \mathrm{~V}$ would only yield very low capacitances. The negative electrode with small capacitances would therefore lead to a low overall total capacitance of the device because $1 / C_{\text {overall }}=1 / C_{\text {pos }}+1 / C_{\text {neg, }}$ where $C_{\text {overall }}$ is the overall capacitance of the capacitor, and $C_{\text {pos }}, C_{\text {neg }}$ are the capacitances of the positive and negative electrodes, respectively. ${ }^{[17]}$

Usually carbon-based electrodes exhibiting good stability at negative potentials are used as negative electrodes to balance the charge from EAP-based positive electrodes. ${ }^{[22-26]}$ However, carbon electrodes only give double-layer capacitances rather than pseudocapacitances; hence, these carbon-based negative electrodes usually display relatively small capacitances and require large mass loadings to meet the charge balance requirement, thereby decreasing the overall specific

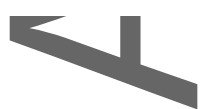

This article is protected by copyright. All rights reserved. 


\section{WILEY-VCH}

capacitances of ASC devices. Recall that the PVFCNT positive electrode displayed large current densities from 0 to $0.5 \mathrm{~V}$. Therefore, we need to identify a negative electrode that offers sufficiently large current densities in the opposite potential window (around -0.5 to $0 \mathrm{~V}$ ). Common carbonbased negative electrodes would yield low overall capacitances, as discussed earlier. We chose a psuedocapacitive conducting polymer PEDOT as the negative electrode because it showed high current densities from around -0.5 to $0 \mathrm{~V}$ versus $\mathrm{Ag} / \mathrm{AgCl}$ (main text Figure $5 \mathrm{c}$ ). The charge balance between the positive and negative electrodes was achieved by using $m_{\text {pos }} c a p_{\text {pos }}=m_{\text {neg }} c a p_{\text {neg, }}$, where $m_{\text {pos, }}, m_{\text {neg }}$ are the mass of the active material on the positive and negative electrodes, respectively, and $c a p_{\text {pos, }} c a p_{\text {neg }}$ are the specific capacitances of the positive and negative electrodes at the respective operation potential ranges, respectively (i.e., 0 to $0.5 \mathrm{~V}$ versus $\mathrm{Ag} / \mathrm{AgCl}$ for PVFCNT, and -0.5 to $0 \mathrm{~V}$ versus $\mathrm{Ag} / \mathrm{AgCl}$ for PEDOT).

\section{Section S8 Supplementary Figures and Tables}

(a)

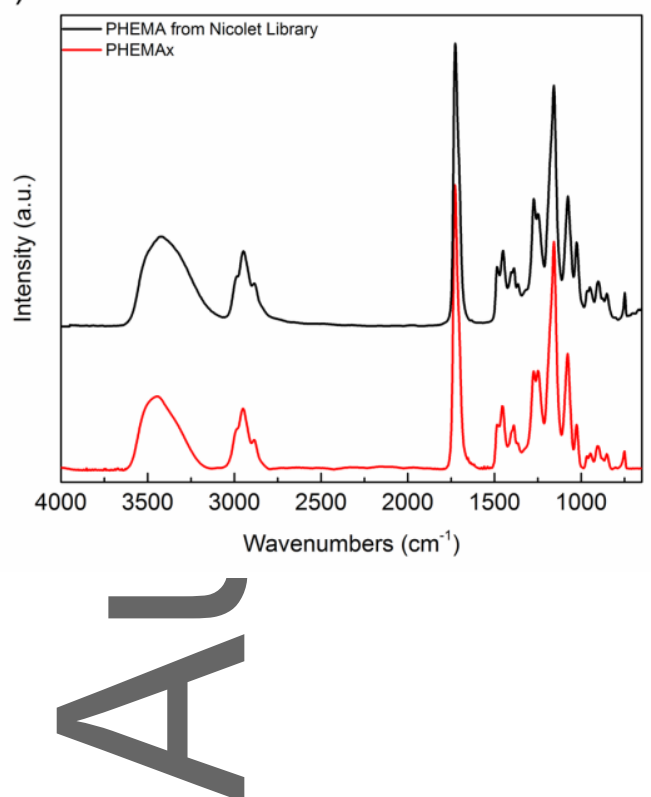

(b)

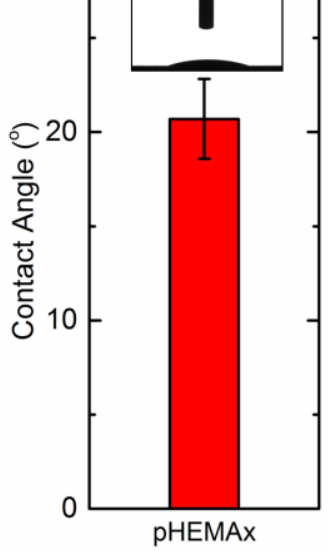

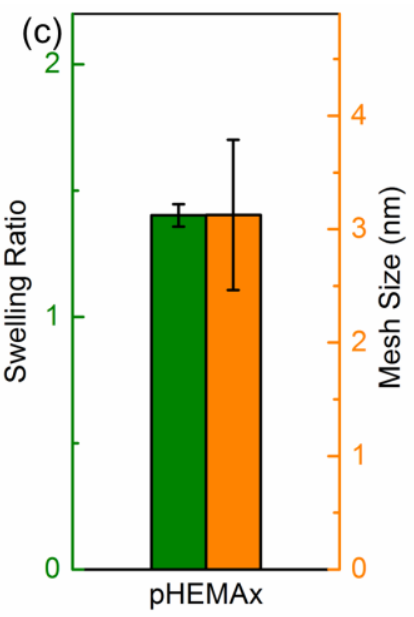

This article is protected by copyright. All rights reserved. 


\section{WILEY-VCH}

Figure S1. Intrinsic properties of PHEMAx. (a) FTIR spectra of iCVD PHEMAx and PHEMA (without the crosslinker) from the Nicolet ${ }^{\mathrm{TM}}$ Sample Library. The overlapping of peaks suggests the retention of HEMA functional groups during iCVD synthesis. (b) Water contact angle of PHEMAx on a silicon wafer substrate. (c) Swelling ratio of PHEMAx and the calculated average mesh size $(\mathrm{nm})$ of the swollen hydrogel.
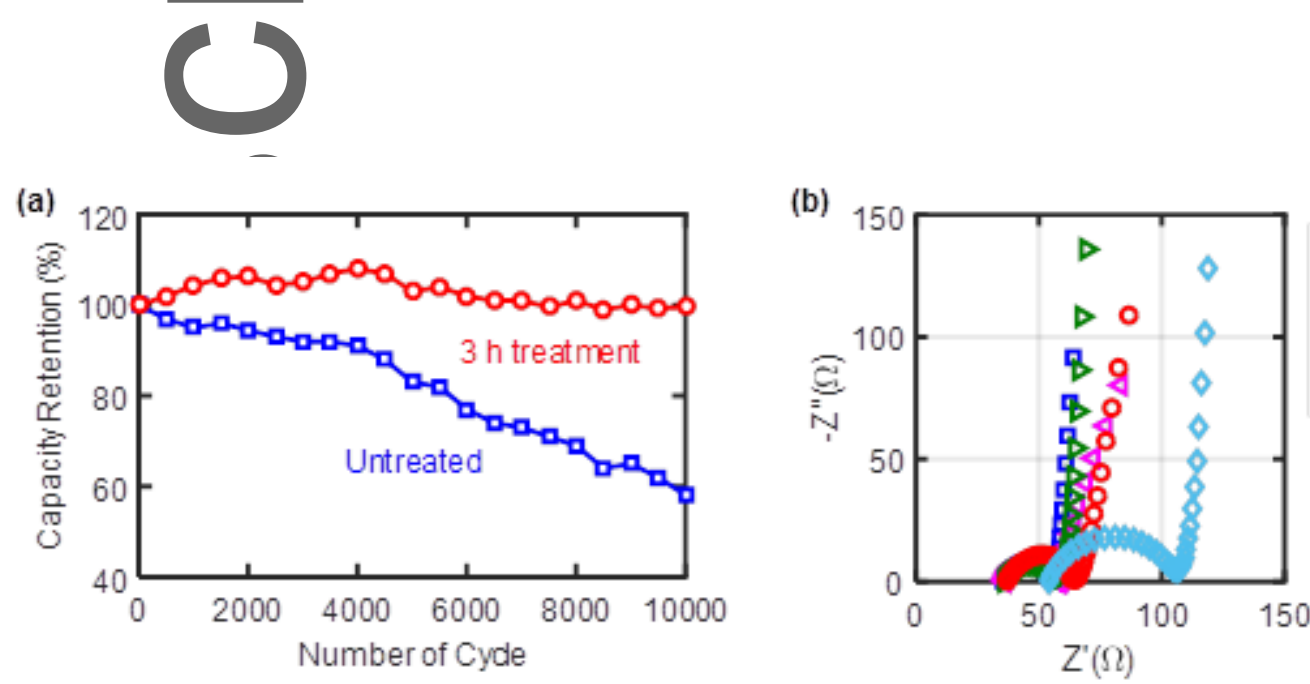
- Untreated
$40.5 \mathrm{~h}$
$>1.5 \mathrm{~h}$
- $3 \mathrm{~h}$
$4.5 \mathrm{~h}$

Figure S2. (a) Capacity retention versus number of GV cycles for untreated PVF/CP and PVF-h/CP with $3 \mathrm{~h}$ iCVD treatment. GV cycling experiments were performed at $1.34 \mathrm{~A} / \mathrm{g}$ for untreated PVF/CP and at $1.23 \mathrm{~A} / \mathrm{g}$ for PVF-h/CP s in $0.5 \mathrm{M} \mathrm{NaClO}_{4}$ using a three-electrode configuration. (b) Nyquist plot for PVF/CP (untreated) and PVF-h/CP with $0.5,1.5,3$ and $4.5 \mathrm{~h}$ iCVD treatment. The EIS measurements were obtained using a $10 \mathrm{mV}$ applied $\mathrm{AC}$ voltage from $100 \mathrm{kHz}$ to $100 \mathrm{mHz}$ in an aqueous solution of $0.5 \mathrm{M} \mathrm{NaClO}_{4}$ with a three-electrode configuration.

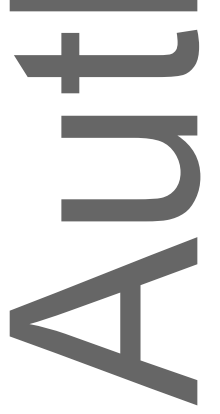

This article is protected by copyright. All rights reserved. 


\section{WILEY-VCH}
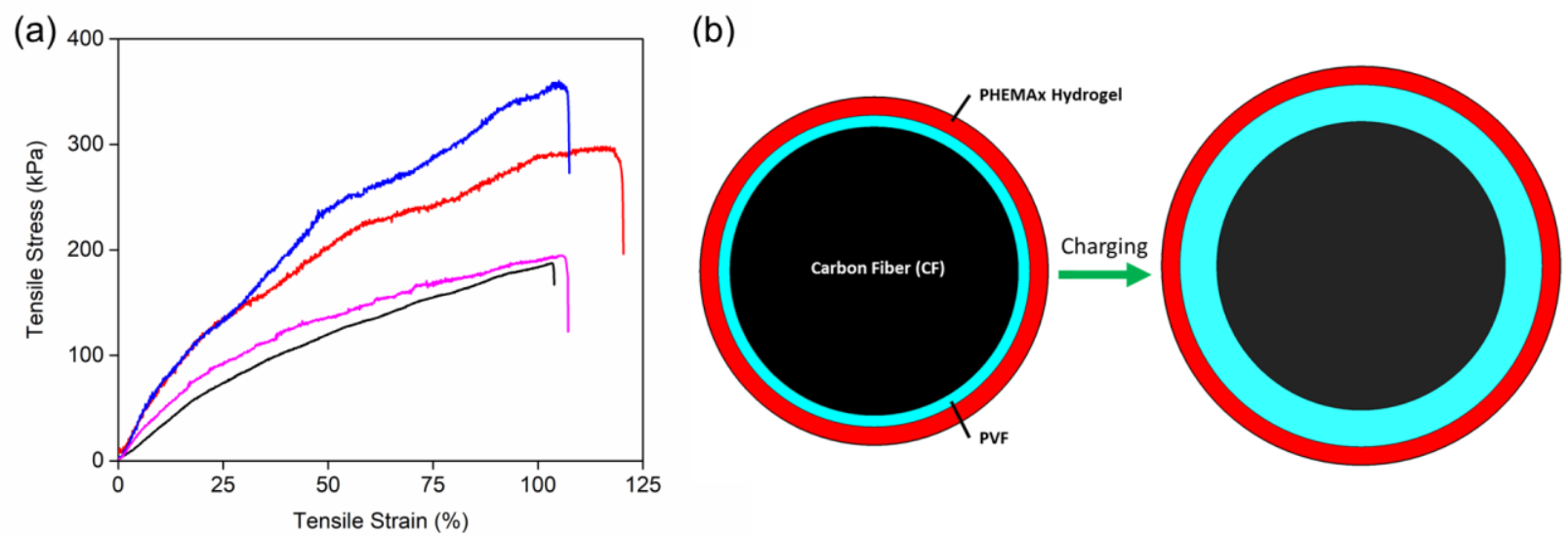

Figure S3. (a) Stress-strain curves of PHEMAx hydrogels ( $n=4)$. (b) Schematic illustration of the swelling of the PVF-h/CF system upon charging (dimensions not to scale).

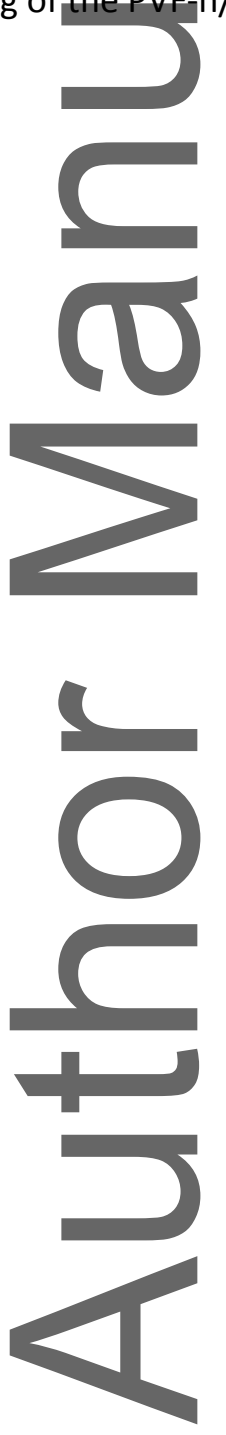

This article is protected by copyright. All rights reserved. 


\section{WILEY-VCH}

(a)

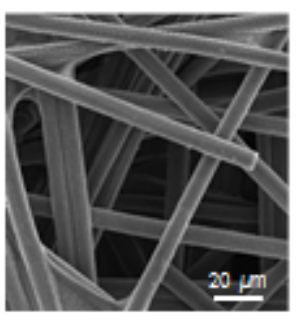

(e)

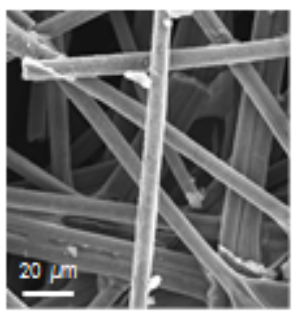

(i)

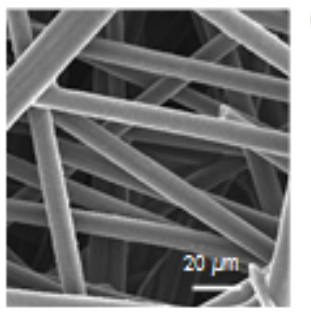

(b)
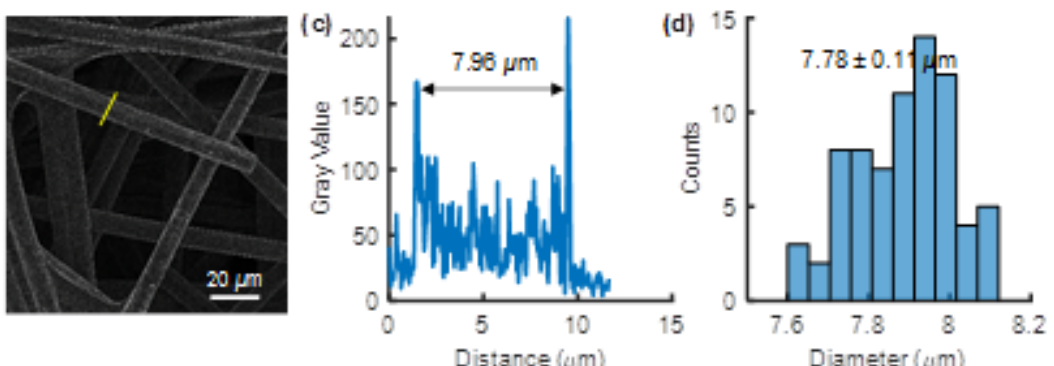

(f)
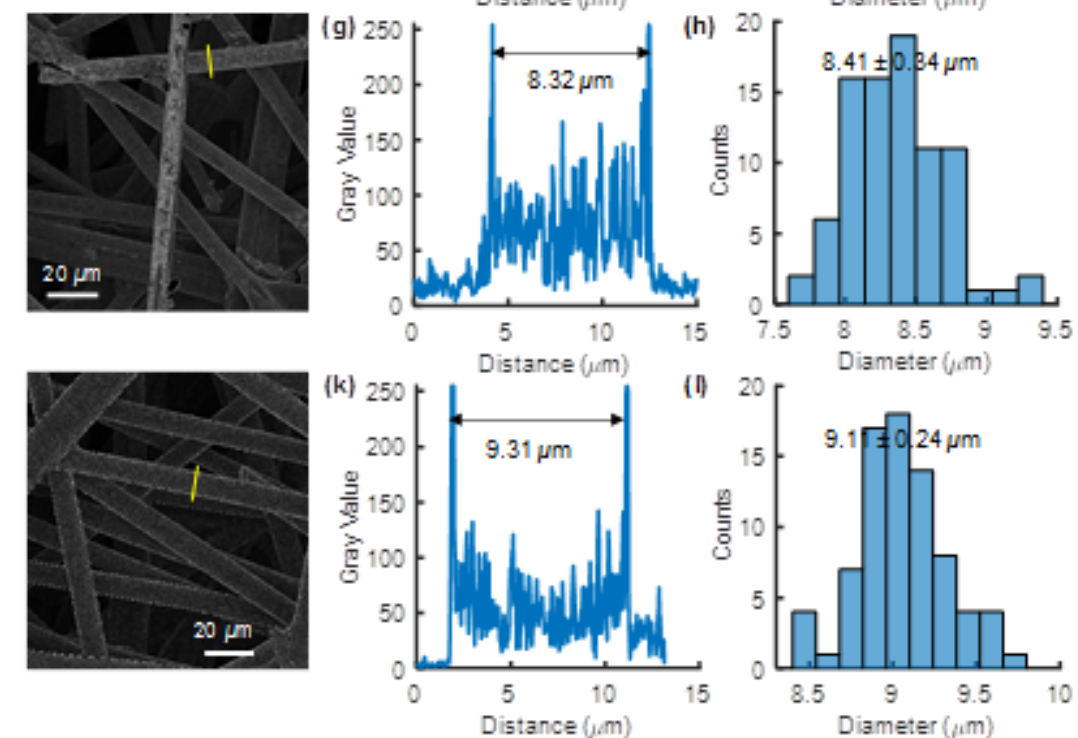

Figure S4. (a) $>$ (d) Determination of average fiber diameters in CP. (a) Representative lowmagnification SEM image of CP. (b) Processed SEM images of CP by edge detection using ImageJ. (c) Representative line profile, indicated by the yellow line in (a), for the determination of the fiber diameter based on the pronounced spikes at the two edges. (d) Histogram of fiber diameter distribution, fitted with a Gaussian function to determine the mean and standard deviation. (e) - (h) Determination of average fiber diameters in PVF/CP. (i) - (I) Determination of average fiber diameters in PVF-h/CP. The PHEMAx coatings of PVF-h/CP were prepared by a $3 \mathrm{~h}$ iCVD treatment.

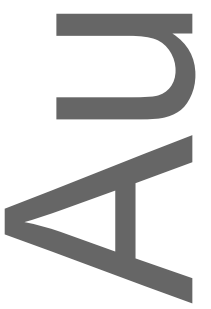

This article is protected by copyright. All rights reserved. 
(a)

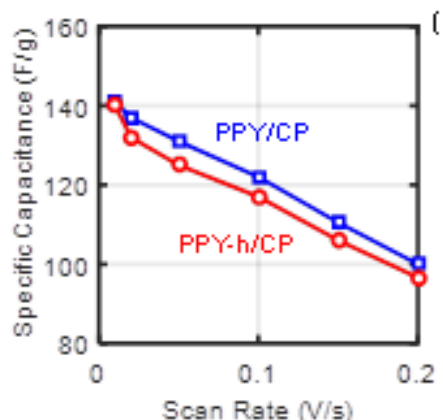

(d)

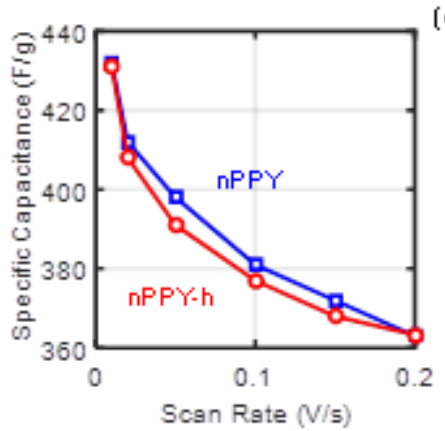

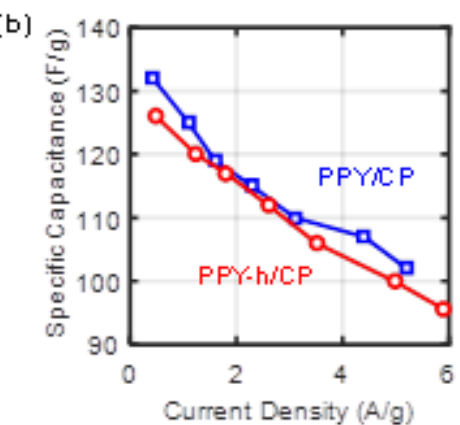

(e)

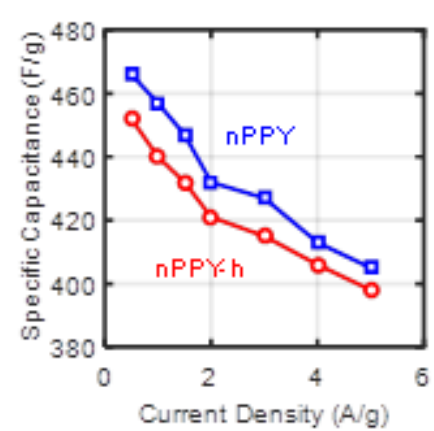

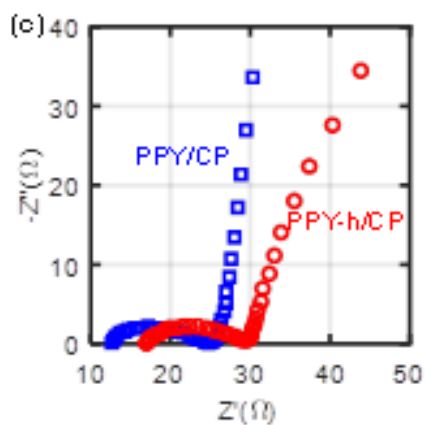

(f)

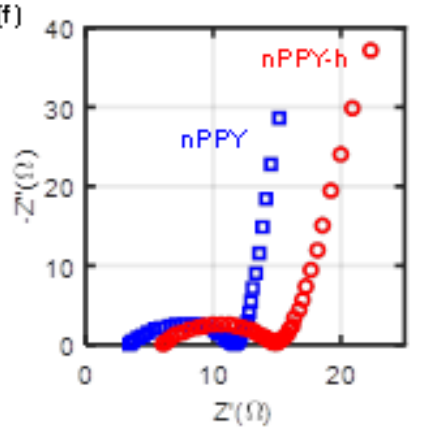

Figure S5. (a) Specific capacitance versus scan rate for PPY/CP and PPY-h/CP obtained by CV measurements. (b) Specific capacitance versus current density for PPY/CP and PPY-h/CP obtained by GV measurements. (c) Nyquist plot for PPY/CP and PPY-h/CP obtained by EIS measurements. (d) Specific capacitance versus scan rate for nPPY and nPPY-h obtained by CV measurements. (e) Specific capacitance versus current density for nPPY and nPPY-h obtained by GV measurements. (f) Nyquist plot for nPPY and nPPY-h obtained by EIS measurements. The coatings for PPY-h/CP and $\mathrm{nPPY}-\mathrm{h}$ discussed in Figure S4 were synthesized by a $3 \mathrm{~h}$ iCVD treatment. The CV, GV and EIS (10 mV amplitude, from $100 \mathrm{kHz}$ to $10 \mathrm{mHz}$ ) experiments were performed in an aqueous solution of $0.5 \mathrm{M}$ $\mathrm{NaClO}_{4}$ employing a three-electrode configuration.

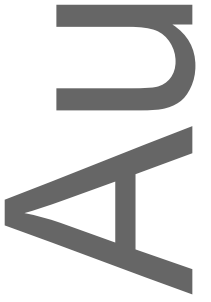

This article is protected by copyright. All rights reserved. 


\section{WILEY-VCH}

(a)

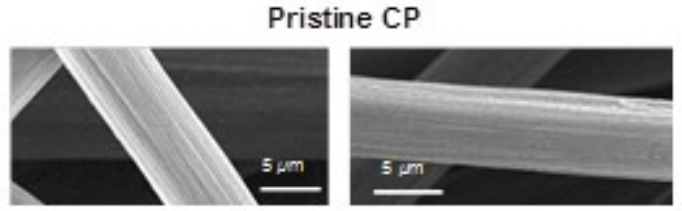

(b)

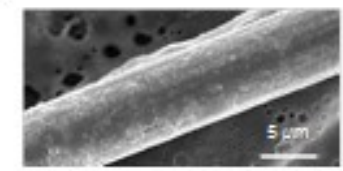

(d)

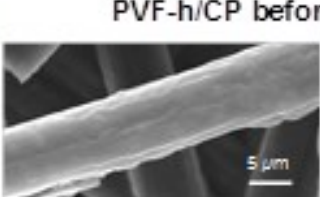

(f)

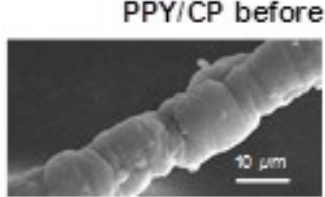

(h)

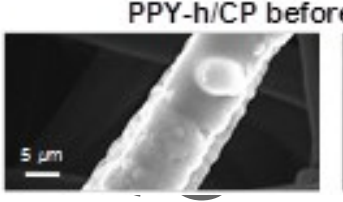

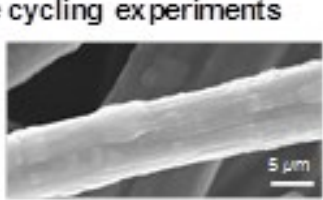
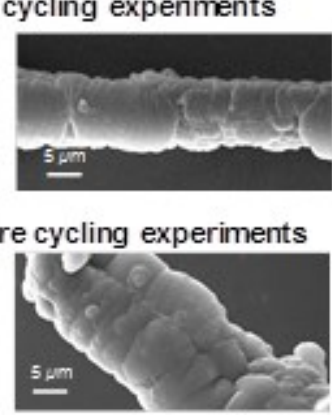

(c)

PVF/CP after cycling experiments

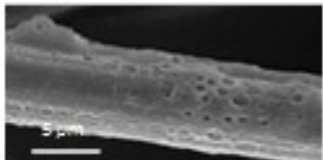

(e)

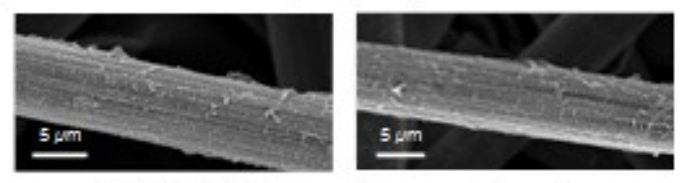

PVF-h/CP after cycling experiments

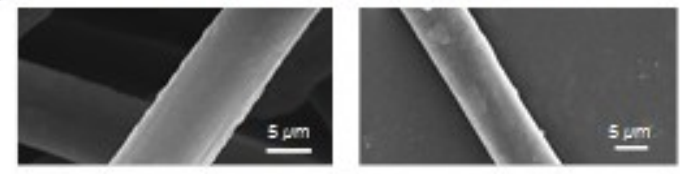

(g)

PPY/CP after cycling experiments

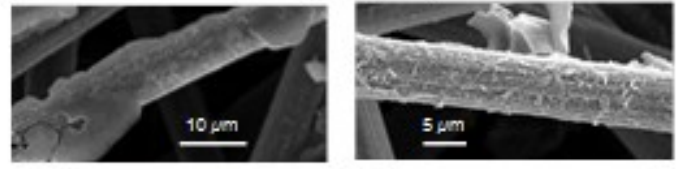

(i)

PPY-h/CP after cycling experiments

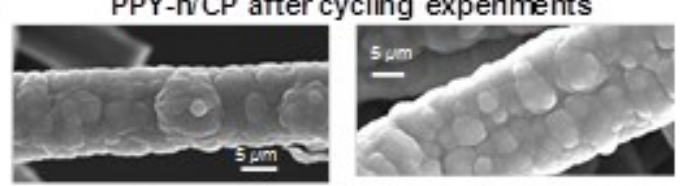

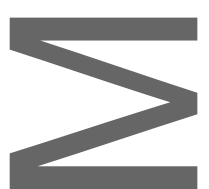

Figure S6. (a) SEM images of pristine CP. (b)(d)(f)(h): SEM images of (b) PVF/CP, (d) PVF-h/CP, (f) PPY/CP, and (h) PPY-h/CP before 10000 CV cycles. (c)(e)(g)(i): SEM images of (c) PVF/CP, (e) PVF$\mathrm{h} / \mathrm{CP}$, (g) PPY/CP, and (i) PPY-h/CP after $10000 \mathrm{CV}$ cycles. $\mathrm{CV}$ was performed at $0.1 \mathrm{~V} / \mathrm{s}$ in $0.5 \mathrm{M}$ $\mathrm{NaClO}_{4}$ using a three-electrode configuration. The PHEMAx coatings of PVF-h/CP and PPY-h/CP were prepared by a $3 \mathrm{~h}$ iCVD treatment.

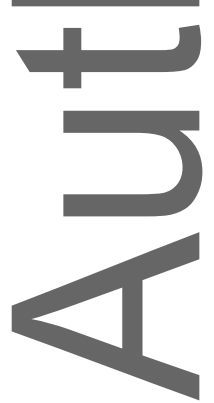

This article is protected by copyright. All rights reserved. 


\section{WILEY-VCH}

(a)

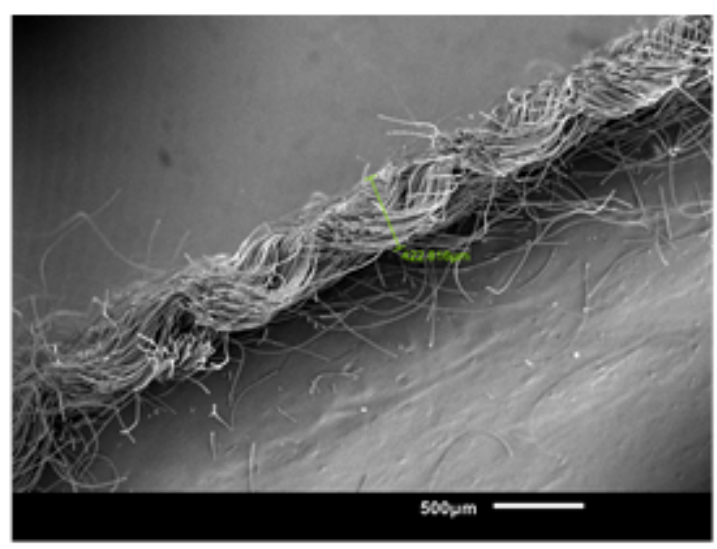

(b)

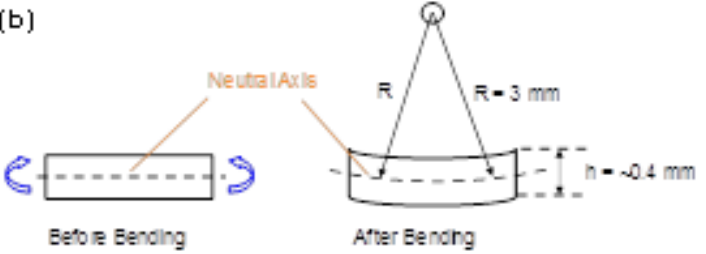

(c)

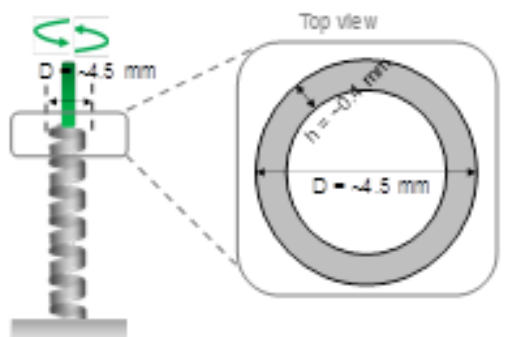

Figure S7. (a) Cross-sectional SEM image of a CC substrate to estimate the thickness of the electrode.

(b) Schematic illustration of the method to calculate the strain during bending tests. The value of $\mathrm{h}=$ $\sim 0.4 \mathrm{~mm}$ is estimated from (a). The maximum strain is calculated as $h / 2 / R=6.7 \%$. (c) Schematic illustration of the method to calculate the strain during twisting tests. The maximum strain is calculated as $h / 2 /(D / 2)=8.9 \%$.
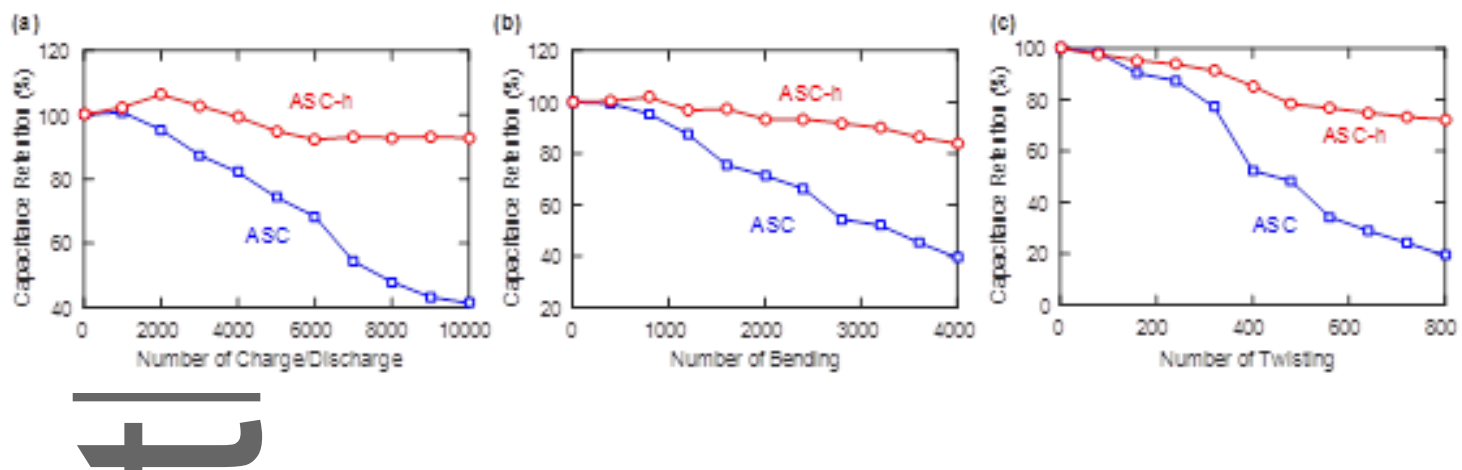

Figure S8. (a) Capacitance retention versus of number of GV cycles for the solid state ASC devices.

GV cycling was performed at 1.2 A/g for ASC and 1.4 A/g for ASC-h. (b) Capacitance retention versus

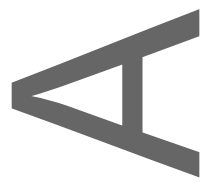

This article is protected by copyright. All rights reserved. 


\section{WILEY-VCH}

number of bending cycles for ASC and ASC-h. The specific capacitances were measured by CV at 0.1 $\mathrm{V} / \mathrm{s}$. (c) Capacitance retention versus number of twisting cycles for ASC and ASC-h. The specific Thesere

capacitances were obtained by CV measurements at $0.1 \mathrm{~V} / \mathrm{s}$.

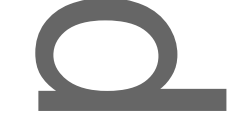

$\square$

Table S1. Sizes of common hydrated ions. ${ }^{[27]}$

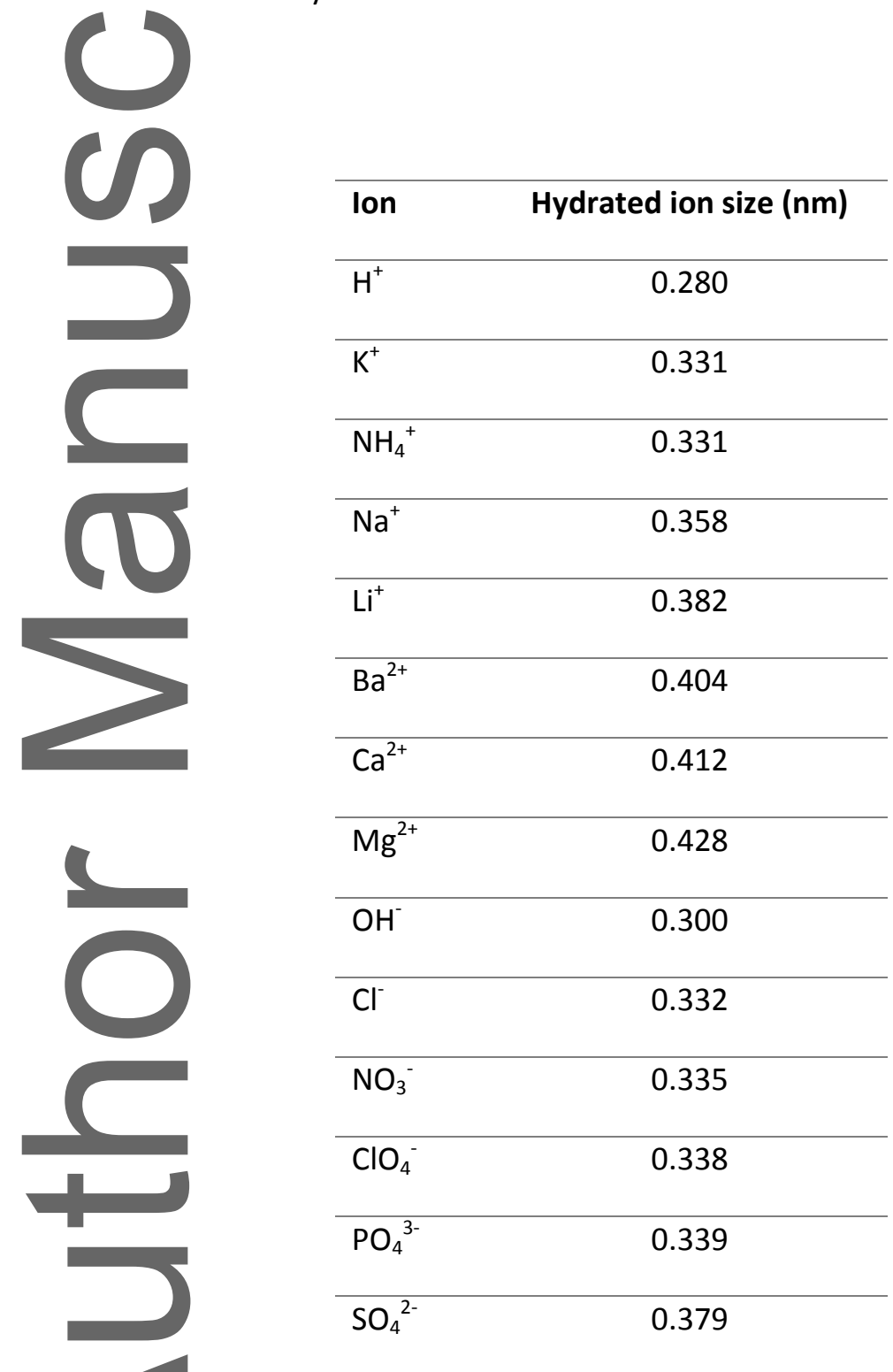

This article is protected by copyright. All rights reserved. 


\section{WILEY-VCH}

$\mathrm{CO}_{3}^{2-} \quad 0.394$

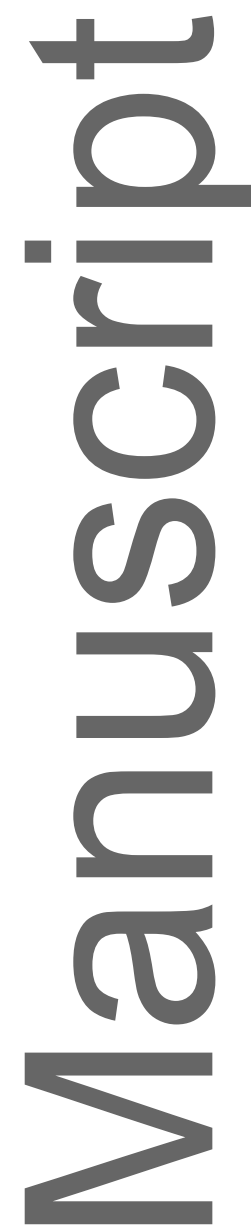

Section S9 References for the Supporting Information

[1] J. L. Yague, K. K. Gleason, Soft Matter 2012, 8, 2890.

[2] K. K. S. Lau, K. K. Gleason, Macromolecules 2006, 39, 3688.

[3] J. M.Cooper, R. Cubitt, R. M. Dalgliesh, N. Gadegaard, A. Glidle, A. R. Hillman, R. J. Mortimer, K. S. Ryder, E. L. Smith, J. Am. Chem. Soc. 2004, 126, 15362.

[4] S. G. Im, K. K. Gleason, Macromolecules 2007, 40, 6552.

This article is protected by copyright. All rights reserved. 


\section{WILEY-VCH}

[5] W. Chen, Z. Fan, L. Gu, X. Bao, C. Wang, Chem. Commun. 2010, 46, 3905.

[6] Z. Lei, L. Lu, X. S. Zhao, Energy Environ. Sci. 2012, 5, 6391.

[7] G. Inzelt, in Conduct. Polym. A New Era Electrochem., Springer Berlin Heidelberg, Berlin, Heidelberg, 2012, pp. 83-147.

[8] X. Mao, W. Tian, J. Wu, G. C. Rutledge, T. A. Hatton, J. Am. Chem. Soc. 2015, 137, 1348.

[9] J. F. Smallex, H. O. Finklea, C. E. D. Chidsey, M. R. Linford, S. E. Creager, J. P. Ferraris, K. Chalfant, T.Zawodzinsk, S. W. Feldberg, M. D. Newton, J. Am. Chem. Soc. 2003, 125, 2004.

[10] T. B. Hunter, P. S. Tyler, W. H. Smyrl, H. S. White, J. Electrochem. Soc. 1987, 134, 2198.

[11] X. F.Wang, B. Liu, R. Liu, Q. F. Wang, X. J. Hou, D. Chen, R. M. Wang, G. Z. Shen, Angew. Chemie-International Ed. 2014, 53, 1849.

[12] T. Q. Lin, I. W. Chen, F. X. Liu, C. Y. Yang, H. Bi, F. F. Xu, F. Q. Huang, Science 2015, 350, 1508.

[13] B. J.Wang, X. Fang, H. Sun, S. S. He, J. Ren, Y. Zhang, H. S. Peng, Adv. Mater. 2015, 27, 7854.

[14] K. Wang, H. P. Wu, Y. N. Meng, Z. X. Wei, Small 2014, 10, 14.

[15] B. C. Kim, J.-Y. Hong, G. G. Wallace, H. S. Park, Adv. Energy Mater. 2015, 5, 1500959.

[16] J. R. Miller, P. Simon, Science 2008, 321, 651.

[17] J.Yan, Q. Wang, T. Wei, Z. Fan, Adv. Energy Mater. 2014, 4, 1300816.

[18] G. P. Wang, L. Zhang, J. J. Zhang, Chem. Soc. Rev. 2012, 41, 797.

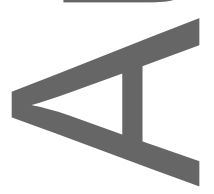

This article is protected by copyright. All rights reserved. 


\section{WILEY-VCH}

[19] C. Zhou, Y. W. Zhang, Y. Y. Li, J. P. Liu, Nano Lett. 2013, 13, 2078.

[20] P. H.Yang, Y. Ding, Z. Y. Lin, Z. W. Chen, Y. Z. Li, P. F. Qiang, M. Ebrahimi, W. J. Mai, C. P. Wong, Z. L. Wang, Nano Lett. 2014, 14, 731.

[21] X. Mao, F. Simeon, D. S. Achilleos, G. C. Rutledge, T. A. Hatton, J. Mater. Chem. A 2013, 1,

[22] J. Yan, Z.J.Fan, W. Sun, G. Q. Ning, T. Wei, Q. Zhang, R. F. Zhang, L. J. Zhi, F. Wei, Adv. Funct. Mater. 2012, 22, 2632

[23] R. R. Salunkhe, J. Tang, Y. Kamachi, T. Nakato, J. H. Kim, Y. Yamauchi, ACS Nano 2015, 9, 6288.

[24] R. R. Salunkhe, J. J. Lin, V. Malgras, S. X. Dou, J. H. Kim, Y. Yamauchi, Nano Energy 2015, 11, 211.

[25] J. L. Liu, L. L. Zhang, H. B. Wu, J. Y. Lin, Z. X. Shen, X. W. Lou, Energy Environ. Sci. 2014, 7, 3709.

[26] G.-F. Chen, X.-X. Li, L.-Y. Zhang, N. Li, T. Y. Ma, Z.-Q. Liu, Adv. Mater. 2016, 28, 7680.

[27] C. Zhong, Y. Deng, W. Hu, J. Qiao, L. Zhang, J. Zhang, Chem. Soc. Rev. 2015, 44, 7484.

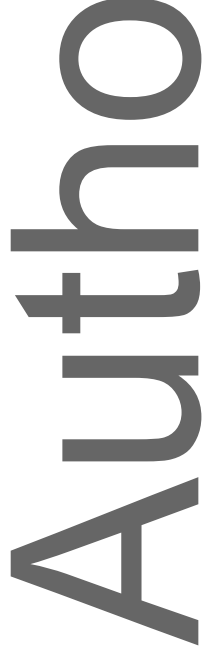

This article is protected by copyright. All rights reserved. 